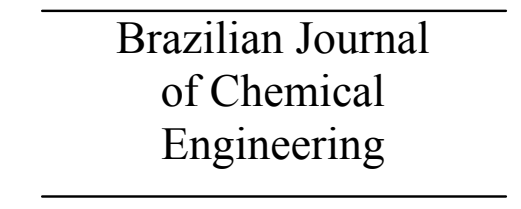

ISSN 0104-6632

Printed in Brazil

www.abeq.org.br/bjche

Vol. 26, No. 02, pp. 227 - 249, April - June, 2009

\title{
THE EVOLUTION AND DEVELOPMENTS OF IMMUNOSENSORS FOR HEALTH AND ENVIRONMENTAL MONITORING: PROBLEMS AND PERSPECTIVES
}

\author{
N. Bojorge Ramírez , A. M. Salgado and B. Valdman \\ Universidade Federal de Rio de Janeiro, Escola de Química, Laboratório de Biossensores, \\ Centro de Tecnologia, Phone: + (55) (21) 2562-7315, Fax: + (55) (21) 2562-7567, Bloco I-164, \\ Av. Horácio Macedo 2030, CEP 21949-900, Cidade Universitária, \\ Ilha do Fundão, Rio de Janeiro - RJ, Brasil. \\ E-mail: ninoska@eq.ufrj.br
}

(Submitted: September 29, 2008 ; Revised: November 12, 2008 ; Accepted: December 9, 2008)

\begin{abstract}
This paper is an overview of the recent developments in immunosensors, which have attracted considerable attention. Immunosensors can play an important role in the improvement of public health by providing applications for which rapid detection, high sensitivity, and specificity are important, in areas such as clinical chemistry, food quality, and environmental monitoring. This review focuses on the current research in immunoassay methods based on electrochemical detection for the analysis of environmental samples or medical diagnostic methods with emphasis on recent advances, challenges and trends. Technological aspects in the development of immunosensors such as kinetics of biomolecular interaction, techniques of immobilization, simplification of assay procedures, immunointeration and catalytic studies and system miniaturization are presented

Keywords: Immunoassay; Protein; Immunosensor; Bioengineering approach.
\end{abstract}

\section{INTRODUCTION}

Since the first biosensor of Clark \& Lyons (Clark, 1992) aiming to detect glucose levels in serum samples, several analytes have been the aim of detection by the development of many biosensors analytical devices that include a biologically sensitive element firmly immobilized or integrated into a physical transducer. Biosensors are one of the most promising lines in the production of analytical devices and monitoring. There is no doubt that the practical use in the medical area, in the food industry and in the monitoring of toxic substances in the environment has greatly stimulated the research and development of biosensors. These researches were stimulated mainly by the demands of clinical analyses and medical diagnoses; in particular, for the fast analysis of clinical preparations, for continuous monitoring in vivo of metabolites, proteins and in the preparations of drugs.

Antibodies are proteins, which are produced in animals by an immunological response to the presence of a foreign substance (with a molecular weight larger than $1.5 \mathrm{kDa}$ ), a so-called antigen $(\mathrm{Ag})$, and have specific affinity for this antigen. In conventional immunoassays, the wells of microtiter plates or tubes are coated with either antibodies or antigens, and after addition of a sample containing its complementary substance, an immunocomplex is formed. For detection, a variety of labels is used. As results of these assays very low levels are detected (acceptable concentrations levels around $10^{-12}$ to

*To whom correspondence should be addressed 
$10^{-9} \mathrm{~mol}^{-\mathrm{L}^{-1}}$ ) of hormones, enzymes, virus, tumor antigens, and bacterial antigens (He et al., 2009; Campàs et al., 2008; Wang et al., 2008).

The immune system is a theme of great interest in investigations due to its powerful capacity of information processing. The main objective of the immune system is to recognize all the cells or molecules in the system and to classify those cells as self or not-self defensive mechanisms. In these assays not only the sensibility is considered, but also the specificity. The immunoassays are widely used in clinical analysis. However, other applications of immunoassays of increasing importance have been observed in other areas, such as in environmental control (Michal et al., 2007; Rodriguez-Mozaz et al., 2005; Velasco-Garcia, 2003) and in the quality control of food (Nandakumar et al., 2008; Skottrup et al., 2008; Choi, 2005; Sadik et al., 2004; Gaag et al., 2003; Shan et al., 2002).

The use of biosensors along the last 20 years has been an approach for immunoassays which has had important and interesting results (Skottrup et al., 2008; Zhu et al., 2005; Wang et al., 1998; Bergveld, 1991). The production of analytic systems that model and simulate living organisms for detecting the presence of certain kinds of substances or organisms is an area with a fast development; it is receiving great attention in the scientific community in the last two decades. In this new field, the development of biosensors involves the identification and the optimization of the analytic system, composed by immobilized biological material, which interacts in a specific way with one or more analytes; in the interface with bio-electronics, this material is coupled to electrodes, which translate a specific interaction by the generation of a signal typically detected through electrochemical, piezoelectric or optical means (Xu et al. 2008; Hirst et al., 2008; D'Amico et al., 2005; Turner et al., 1987). However, biosensors are different from the existing techniques in at least two very useful and fundamental aspects: the first of them is the intimate contact of the biological material (whole cells, tissue, antibodies or enzymes) with a transducer that converts the biological signal into a measurable signal (Theâvenot et al., 1999); and the second aspect is its functional size. The sensitive portion of a biosensor is usually small and it allows small sample volumes and a minimum interference with the existent processes after the implementation.

This review aims to explore key characteristic in the design and development of immunosensors, with emphasis in the amperometric ones, which allow a fast and sensitive detection in a system that can be automated and miniaturized. Their potential of commercialization is increasing, because they allow solving great scale problems, such as problems in the areas of health, pharmacy and environment. A comparison is also presented of the analytic capacities of several kinds of immunosensors, which constitute a particular interest area of biochemical engineering.

The biological materials can be selected in order to satisfy analytic needs, operating in several specificity levels. They can be highly selective, specific for a narrow margin of compound, or to show a wide specificity spectrum such as a sensitive biosensor, for example, only to one antibiotic (for instance, the gentamicin) or then to all the antibiotics. This flexibility in selecting the biological materials allows the user to adapt the biosensor to his or her needs. Biosensors based on the antigen antibody interactions or haptens as biosensitive elements are called immunosensors, which combine the sensitivity and specificity of immunoassays with physical signal transduction.

Transducers convert the physical-chemical interaction between biomolecules and their specific analytes into a signal, which is amplified and registered as an analytical result. Immunosensors are built by means of the appropriate combination of the biomolecule (antibody polyclonal, antigen, hapten) with the transducer (electrochemical, amperometric, potentiometric, piezoelectric, optical, etc.); used together, they can be applied in specific analytical situations. In the classical biosensor, the receptor is usually immobilized onto the transducer surface, which enables it to detect interaction with analyte molecules. In contrast to immunoassays, immunosensors commonly rely on the reuse of the same receptor surface for many measurements. It has already been shown by various authors that the antibody layer was largely secured during sensor reuse, which might imply an economic advantage of the immunosensor compared to commercial kit assays like ELISA The reusability is evaluated as an important feature of biosensor. Between assays, the regeneration of the used immunosensor has been carried out by stirring in basic solution $(\mathrm{NaOH} / \mathrm{NaCl})$ or more commonly by use of glycine/ $\mathrm{HCl}$ buffer solution $(\mathrm{pH} 2$ - 3) for few min, and then by washing with distilled water several times to desorb the binding antigens. (Wang Z. et al., 2008; Liu et al. 2008; Wang S. et al., 2008). Direct signal generation potentially enables real-time monitoring of analytes, thus making immunosensors suitable tools for continuous monitoring. Also factors such as progresses in microelectronics, electrochemistry and production of optical fibers and 
nanotechnology have contributed to the development of several detecting elements. Thus, the integration of these technologies makes possible the production of immunosensors applicable to a wide variety of detection and monitoring problems.

In October of 2008 the Global Industry Analysts, Inc (http://www.strategyr.com/), reported that several factors has motivated the use of biosensors in industrial, environmental, and especially medical diagnostic applications. Thus, the world market for biosensors is estimated to reach $\$ 6.1$ billion by 2012 . The growing population, rising incidences of chronic diseases, such as, diabetes, and the growing need for environmental monitoring, are all factors expected to prop up growth in the upcoming years.

\section{BIORECEPTOR MOLECULES AND IMMUNOASSAYS}

The bioreceptor molecules of an immunosensor are the antibodies. The antibodies are also called immunoglobulins, because they are proteins related to the immunological system. The immunoglobulin $\mathrm{G}(\mathrm{IgG})$, the main antibody in the serum, consists of four polypeptides: two heavy chains and two light ones, joined to form a "Y" shaped molecule. The amino acid sequence in the tips of the "Y" varies greatly among different antibodies. This variable region, composed of 110-130 amino acids, give the antibody its specificity for binding the antigen. The variable region includes the ends of the light and heavy chains. Each $\mathrm{Ab}$ has a unique structure that attaches to an antigen in a lock-and-key fit. When the $\mathrm{Ab}$ is attached to the $\mathrm{Ag}$, the antigen is destroyed or marked for destruction or elimination by some other method. The constant region determines the mechanism used to destroy antigen. The antibodies are divided in five main classes, $\operatorname{IgM}, \operatorname{IgG}, \operatorname{IgA}, \operatorname{IgD}$ and $\operatorname{IgE}$, according to the structure of the constant area and its immune function. The literature offers a great amount of references with detailed information on antibody structures (Briand et al., 2006; Subramanian et al., 2004; Bao et al., 2002; Schuetz et al., 1999) and there are also structural databases of proteins. It is also possible to find tutorials that explore many current purification methods as new emergent technologies. Subramanian et al. (2004) show an evaluation of the current progresses applied to the production of monoclonal antibodies, industrial strategies, importance of antibody fragments, application of chromatographic methods, quality control, virus removal and bio-security.

In the tests of an immunoassay, in order to detect the interaction between the antibody and the antigen, one of the immunoagents must be conjugated or modified by joining it to specific molecules or biological markers, to facilitate either the capture or the detection of the analyte. Several biological labels are commercially available in a wide range of styles (See Table 1), of which the radioactive ones were initially used, due to their inherent sensibility. Later, the restriction in relation to the use of radioisotopes led to the use of other markers, such as chemiluminescent compositions and enzymes (for instance, alkaline phosphatases, horseradish peroxidases), which convert the substrate of the enzyme into a measurable product (Bratov et al., 2008; González-Martínez et al., 2006; Hoefelschweiger et al., 2005; Gosling et al., 1997).

Table 1: Types of labels used in immunoassays

\begin{tabular}{|l|l|}
\hline Biochemical Marker & Example \\
\hline Radioisotopes & ${ }^{14} \mathrm{C},{ }^{3} \mathrm{H},{ }^{32} \mathrm{P},{ }^{125} \mathrm{I},{ }^{57} \mathrm{Co}$ \\
\hline Fluorophores & $\begin{array}{l}\text { Fluoresceina, umbelliferone, Rhodamina, rare earth } \\
\text { chelates. }\end{array}$ \\
\hline Chemiluminescent & $\begin{array}{l}\text { Luminol and derivates } \\
\text { Luciferase / Luciferin }\end{array}$ \\
\hline & $\begin{array}{l}\text { Alkaline Phosphatase, Horseradish Peroxidase (HRP), } \\
\text { Glucose-6- phosphate dehydrogenase (G-6-PDH), } \\
\text { Malate dehydrogenase (MDH) }\end{array}$ \\
& NADH dehydrogenase, acetylcholinesterase \\
\hline Particles & $\begin{array}{l}\mathrm{Fe}_{3} \mathrm{O}_{4}, \text { Latex, Red cells. nanosilica SiO } \\
\text { labels }, \text { nanomagnetic }\end{array}$ \\
\hline Metallic Ions & Au ${ }^{3+}$ \\
\hline \multirow{2}{*}{ Other } & $\begin{array}{l}\text { Enzymatic Cofactors (FAD) } \\
\text { Enzymatic Substrates } \\
\text { Proteins } \\
\text { Ionophore }\end{array}$ \\
\hline
\end{tabular}


(a)

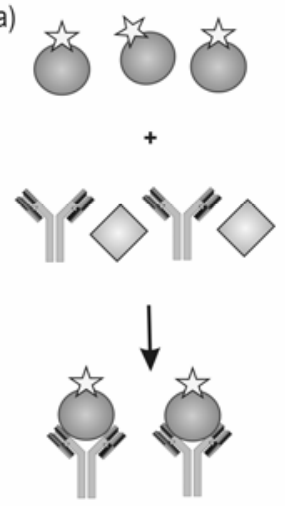

(b)
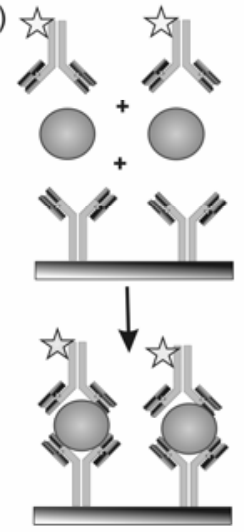

(c)
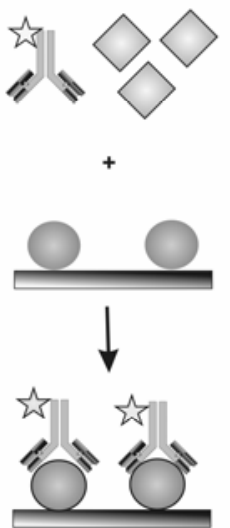

(d)
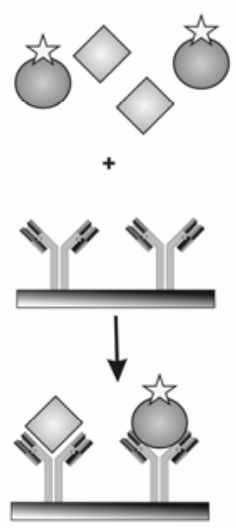

Legends:

Antigens: $\bigcirc \bigcirc$; Antibody: $=$;

Label: $\hat{\imath} ; \quad$ Solid phase:

Figure 1: Generally used formats: (a) a homogeneous competitive immunoassay, (b) a heterogeneous non-competitive immunoassay, (c) a heterogeneous competitive immunoassay and (d) a heterogeneous competitive immunometric assay.

Among the different immunoassay formats described in the literature (Stolpera et al., 2007; Tschmelaka et al., 2004; Matsunaga et al., 2003; Sadana et al., 2002; Warsinke et al., 2000), four of them are more commonly used (see Figure 1). In a homogeneous immunoassay (Figure 1a), the antibodies, antigens and labeled antigens are mixed. The antigens freely marked and those which are linked to the antibodies can be distinguished by a change of activity of the marker when coupled. The immunoassays are usually heterogeneous, which means that the antibody or the antigen is immobilized in a solid support and an immunocomplex is formed upon entering into contact with a solution containing the other immunoagent. The non-linked proteins are removed by washing and the answer obtained from the labels is proportional to the amount of linked protein.

The more common kind of enzymatic immunoassay used in clinical analyses is known as Enzyme Linked Immune Sorbent Assay, or ELISA. There exist different schemes of enzymatic immunoassays (of competitive and non-competitive type) and, in the clinical analyses practice, two of the most popular methods are the sandwich method and the competitive immunoassay method (Harlow and Lane, 1988).

In a non-competitive sandwich immunoassay, the antibodies are immobilized and, after the addition of the sample which contains the antigen, a conjugated or secondary labeled antibody is added (Figure 1b). In a competitive assay, the competition happens between the free and the linked antigen for a limited amount of labeled antibody (Figure 1c) or between the antigen (sample) and the labeled antigen for a limited amount of antibodies (Figure 1d). In the case of the immunosensors, direct assays have been more frequently applied. The most common formats in this field, of fast detection, are the competitive assays and the sandwich assays.

The limitation of sandwich analysis is that this cannot be used for hapten determination (analytes of low molecular weight). The small size of those molecules just allows the immunointeraction with an antibody molecule. In a general sense, sandwich analysis schemes give the lower detection limit, resulting in analyte concentrations analyzed in picomolar ranges.

The conventional immunoassay techniques are convenient for analytical practice with a great number of analyses (frequently identical) and are commonly used. However, these techniques can only be used in hospitals and laboratories especially equipped with personnel with technical training. The automation of the measures of this multi-step procedure is difficult (Farré et al.2007; Ghindilis et al., 1998, 1997). Consequently, the time for analysis through conventional immunoassays usually goes from one to several hours; it makes this technique inadequate for the fast determination of analytes.

The basic principles of the alternative immunoassay methods are similar to the conventional immunoassay techniques. In the alternative assays, also based on the discovery of interaction of the antigen-antibody, several approaches are used, such as the development of: (i) discovery methods highly sensitive for the label; (ii) improved immunointeraction schemes; (iii) kinetic studies of these immunointeractions, (iv) automated immunoassay schemes and, (v) miniaturization. 


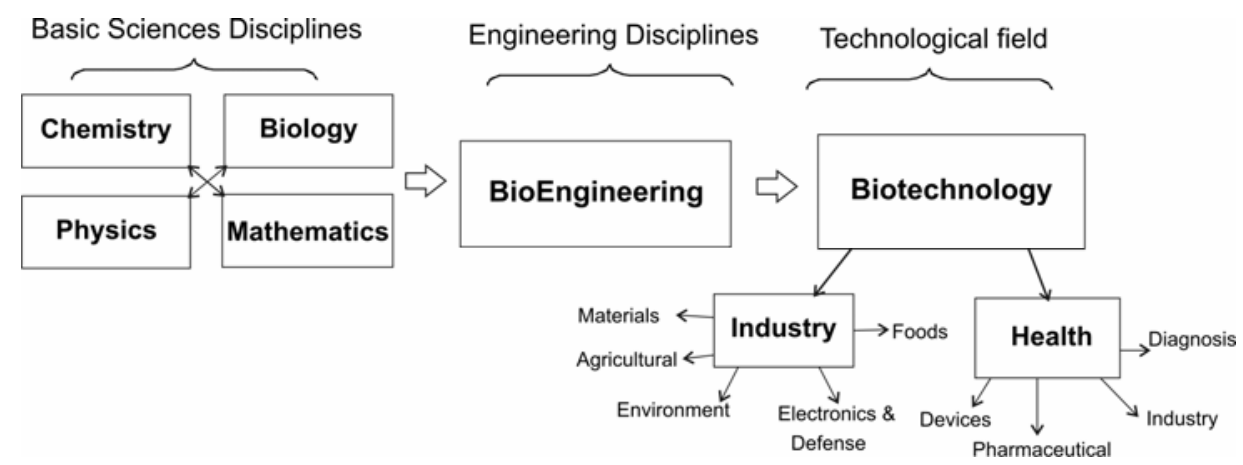

Figure 2: Multi-disciplinary character of Biochemical Engineering

\section{TECHNOLOGICAL ASPECTS IN THE DEVELOPMENT OF IMMUNOSENSORS}

Biochemical Engineering, through basic disciplines such as Physics, Mathematics, Biology and Chemistry and the disciplines of Bioengineering, have become one of the most exciting areas of the last decades for their interdisciplinary character. This has allowed the generation of series of scientific results that were transferred to environmental projects, industrial biotechnology, agriculture, and to the area of health care (see Figure 2). Two decade ago the biosensors were not massively applied to industrial process monitoring and control. On the other hand, the biosensor has been adapted to a biological system. It is also suitable for very fast in situ measurements of components that are extremely difficult to sample because of the heat sensitivity of the biological receptors and only a few of them were used as specific detectors in FIA systems for on-line process monitoring (Adányi et al., 2007; PrietoSimón et al., 2006; Schugerl, 2001; Schmidt, 1993). However, the presence of researchers with an engineering profile is currently observed more and more in the development or immunosensors applications for the detection of several compounds. With the integration of microelectronics and molecular biology, together with the advances that combine biotechnology with nanotechnology and information processing, a new generation of devices promises many solutions for environmental monitoring and biochemical processes.

Some of the technological aspects for the development of immunosensors are the kinetics of antigen-antibody biomolecular interactions, immobilization methods, procedures of assays, immunointeraction with the transductor surface and the application of catalytic antibodies and are discussed below.

\section{(i) Kinetic Studies of Biomolecular Interactions}

The success of the detection scheme by means of immunosensors will be significantly improved if better understandings of the different stages involved in the detection process are obtained. In this context, Sadana et al. (2002) present several studies on the interaction kinetics in the linking of the compound $\mathrm{Ag}-\mathrm{Ab}$ and the influence of the diffusion rate and variable coefficients of adsorption. The authors suggest that the dual-step connections for antigen in solution and the antibody immobilized on the surface exhibit a second order kinetics $\left[\frac{\mathrm{d} \Gamma}{\mathrm{dt}}=\mathrm{k}[\mathrm{Ag}]^{2} \Gamma_{0}\right]$ in relationship with the concentration of the antigen [Ag] close to the surface, where $\Gamma_{\mathrm{o}}$ is the total concentration of the Ab sites on the surface; $\Gamma$ is the surface concentration of antibodies that are bound by antigens at any time $\mathrm{t}$; and $k$ is the reaction rate constant. In the case of the antibody in solution for the antigen immobilized on the surface, it exhibits a first order dependence, both for the antibody concentration close to the surface $[\mathrm{Ab}]$, or to the antigen $[\mathrm{Ag}]$ on the available surface for connection - $\left[\frac{\mathrm{d} \Gamma}{\mathrm{dt}}=\mathrm{k}[\mathrm{Ag}][\mathrm{Ab}] \Gamma_{0}\right]$. In relation to the adsorption rates, they observed that, when there exists an increase in the coefficient of the adsorption rate with time, the concentration of antigen close to the surface decreases. In the same way, with the decrease of the adsorption rate coefficient with time, the antigen concentration close to the surface increases. Other aspects of interest in the kinetic study of biomolecules are the effects of the analyte concentration in the solution, sample $\mathrm{pH}$, different 
surfaces effects, regeneration effects, temperature, influence of the flow rate etc.

In this same context, on kinetic studies used for biosensor technology, a recent work by Nordin et al. (2005) presents a study of eight different kinds of representative kinases of a great family of proteins. Through the kinetic study, the authors found the critical conditions of immobilization, which allowed them to create strategies to preserve the coupling capacity for the inibitors and for the developed ATP. The assays presented by the authors also include kinetic characterization of inhibitors that couple to kinases and coupling characteristics in the presence of ATP to identify competitive ATP binders.

\section{ii) Techniques for Biomolecule Immobilization}

Techniques for biomolecule immobilization should allow a stable bond between the sensorial surface and the bioreceptor, without interfering with the biological activity of the biomolecule. This is a key aspect in immunosensor assembly. In heterogeneous assays, immobilizing the antibody or the antigen in the solid support frequently requires several wash steps and blocking in order to remove the excess reagent and to cover new immobilization sites. General strategies for immobilizing the immune reagent on the electrode surface include: physical adsorption, entrapment in a polymeric matrix and covalent attachment. Among these methods, physical adsorption has exhibited capacity for assuring the protein activity, but the forces involved can produce weak interactions with the surface and can suffer desorption (Zhou et al., 2003a,2003b,2002; Walcarius et al.1998).

Another method currently used in some applications is the method of entrapping the protein on the polymeric membrane surface (Jiang X. et al., 2008; Darain et al., 2003; Liu et al., 2003; Naqvi et al., 2002; Rabinovich et al., 2001). In the case of optical detection, for instance when this method is applied in total internal reflection fluorescence immunosensors (TIRF), it is necessary to ensure that the antibodies in the evanescent wave zone, very close to the optical surface, are very well trapped in the polymer so as to be optically transparent. The use of Nafion for antibody entrapment was explored in order to immobilize antibodies or antigens. Susmel et al. (2005) studied the performance of a piezoelectric immunosensor prototype in which the immobilization of the Bacillus cereus antibody on the crystalline surface was accomplished by simple entrapment within a thin Nafion film. In other words, an ion exchange is performed in a very porous polymer material that exhibits a good attachment to gold. In a similar way, Nafion has also been widely used in amperometric immunosensors (Agui et al., 2008). For example, a novel immunosensor was recently proposed by $\mathrm{Wu}$ et al. (2008) that is based on gold nanoparticles assembled onto the TMB/Nafion film modified electrode to provide active sites for the immobilization of antibody (antiMIgG) molecules. Another amperometric immunosensor is based on gold nanoparticles/ thionine/Nafion-membrane-modified gold electrode for determination of $\alpha$-1-fetoprotein (Zhuo et al., 2005), Zhou et al. (2003b) described another amperometric immunosensor for the assay of the antibody of Schistosoma japonicum, where the polyanionic perfluorosulfonated Nafion polymer was used to modify the glassy carbon electrode as a platform for the immobilization of $S$. japonicum antigen. In this same line, our research group proposed an immunosensor for detecting the antibody anti-apyrase of $S$. mansoni based on rigid composite materials, containing graphite powder and epoxy resins, A surface modification strategy for the use of oxidized graphite in the detection of antibodyantigen interaction was developed. This modification strategy is based on silanization of a conductive composite (Bojorge et al., 2007).

Another well-known immobilization method is the covalent attachment of a protein to an inorganic or organic surface (Quan et al., 2004a, 2004; Divya et al., 1998). This method is potentially more aggressive, but it can produce an almost irreversible immobilization of the protein onto the sensor surface, which allows reusing the sensor after washing procedures or regeneration. Tedeschi et al. (2003) established new immobilization methods applied to covalent TIRF sensors such as: (a) GOPS-dextran method, which consists in tying the antibody in a covalently bonded activated dextran matrix to the surface through GOPS (glycidyloxypropyl-trimethoxysilane); (b) $\mathrm{NaIO}_{4} / \mathrm{AADH}$ method: sacharideus oxidation in the fragment $\mathrm{Fc}$ of the antibody using periodate $\left(\mathrm{NaIO}_{4}\right)$ and its connection to surfaces activated with hydrazide; (c) GOPS/F( $\mathrm{ab}^{\prime}$ ) method, where the antibody fragments $F\left(a b^{\prime}\right)$ are linked to the surface activated with GOPS; (d) APTS/Sulfo-SMCC method: fragments of the antibody, linked to an APTS (3-(2-aminoethylamino) propyl-trimethoxysilane).

There are several studies on protein immobilization and, particularly, several procedures 
for antibody immobilization for immunosensors (Iyer et al., 2008; Babacan et al., 2000; Schuetz et al., 1999; Shriver-Lake et al., 1997). However, there is no method for standard immobilization with results that can be reproduced in order to use them to evaluate new methods. This is because there are several surfaces that can be used and, besides, the density of the immobilized protein surface depends highly on the nature, origin and history of the protein used. Moreover, variables such as the pre-treatment and nature of the substrate, washing protocols etc., can have wide variations. For this reason, it is necessary to be careful when comparing numerical results among publications, since surface densities can vary significantly (Kandimalla et al., 2004).

\section{iii) Simplification of Assay Procedures}

Another aspect of interest is the simplification of assay procedures. This can be achieved by reducing the number of stages of the assays, decreasing the amount of chemical substances involved in the procedure and its automation (Ordóñez and Fàabregas, 2007; Carnes and Wilkins, 2005; Tschmelaka et al., 2004; Matsunaga et al., 2003; Neel et al., 1998). The simplification of the assay strategy is an essential development for the commercial success of immunosensors. The problems associated with assay simplification stem from the fact that immune recognition is not accompanied by an easily detectable event. Direct methods such as those based on optical systems have circumvented such problems by measuring mass changes. However, such devices are not so amenable to instrumental simplification. Electrochemical methods have so far offered the best prospects for commercial biosensors. Success has only occurred with enzyme-based biosensors measuring simple biochemical molecules such as glucose, lactate and creatinine. The use of antibody-based assay strategies requires the introduction of electrochemical labels. Introduction of such species results in greater complexity, accompanied by a series of assay steps. This extension in assay complexity is in direct opposition to the concept of the biosensor: simplicity. Thus, the use of bioreagents commercially available is recommended. Several strategies have been taken to remove these assay steps and reduce the complexity of the immunoassay. Such strategies may contribute to the application of immunosensors as a serious commercial proposition.

\section{iv) Immunointeraction}

Immunointeraction of proteins in solution with their complementary proteins immobilized on a surface does lead to changes in, for example, refractive index, thickness and dielectric constant of the immobilized layer. With proteins immobilized, for example, on a piezoelectric material, a change in resonance frequency is detected which is proportional to the mass change on the surface. These properties are exploited in optical, electrochemical and piezoelectric immunosensors. Ideally, immunosensors are devices with a fast response, a high specificity and sensitivity. Preferably, immunosensors are also regenerable, which means that they can be reused immediately or after dissociation of the Ab-Ag complex, e.g., by using a chaotropic reagent (Kandimalla et al., 2004).

The immunointeraction can be improved by using homogeneous schemes and assays based on high area-volume ratio. Determining the immunosensor sensibility versus the immunointeraction implies the development of highly sensitive methods for determining labels that improve the transduction performance of the measured signal. In this context, it is possible to mention the projects accomplished at bioengineering laboratories over the immunointeraction characteristics and their applications for separation and analysis (Sada et al., 1990) and the characteristics of liposome in immunoabsorbent assays (Kumada et al., 2001), respectively.

\section{v) Catalytic Studies}

The application of catalysis of chemical reactions is another challenge in the area of immunosensors. The production of catalytic antibodies requires great ability in the selection of one among 1012 possible antibodies linked to any molecule of interest. With this ability, the immune system becomes an attractive source of potent specific catalysts. By using protein engineering, the enzyme catalysis can still be improved, perhaps surpassing the activity of natural enzymes. Through classic hybridoma techniques, molecular biologists have developed cloning methods for the array of genes that codify IgG molecules, which involve four typical stages: (a) immunization of the mouse with conjugated haptenprotein carrier; (b) hybrid clone generation, immortalized through the fusion of splenic cells and myeloma cells coming from mice or rabbits ; (c) 
selection of individual clones for specific linking of the antibody to the hapten; and (d) selection of antibodies which exhibit the wanted catalytic activity. A mathematical analysis to describe a distribution of Michaelis-Menten antibody catalysts could to be performed to help to interpret the results. However, it is essential that the catalytic antibodies are completely purified from possible endogenous enzyme contamination, which can catalyze the same kind of reaction in study. Catalytic antibodies have great potential in the pharmaceutical industry (Feng et al. 2008; Khorasani-Motlagh et al., 2004; Schuetz et. al., 1999).

\section{vi) System Miniaturization}

Another aspect is the system miniaturization of sensors and, in some cases, the simplification of assay procedures. All these advances have generated an increasing demand for miniaturized and portable solutions. The miniaturization of immunosensors allows the application in medical diagnoses at home, in the field of environmental monitoring, in the scientifical detection of crimes, in the supervision of quality in small food industries etc. Suzuki et al. (2001) from the Department of Biochemical Engineering of Kyushu Institute of Technology, together with researchers from the Department of Electric and Electronic Engineering of the University of Toyama, developed a chip and a miniaturized SPR immunosensor for detecting human $\mathrm{IgG}$ and molecules such as pesticides and dinitrophenol. The size of the sensor is just $22 \mathrm{~mm}$ width $\mathrm{x} 30 \mathrm{~mm}$ length. Zhou et al. (2003b) developed an electrochemical immunosensor of carbon paste of $6.00 \mathrm{~mm}$ id. And Yoon et al. (2004) developed an immunosensor system for ferritin analysis, consisting of two rectangular gold and titanium electrodes of $10 \mu \mathrm{m} \times 500 \mu \mathrm{m}$ and circular electrodes with $50 \mu \mathrm{m}$ radius.

When designing an immunosensor, besides determining the assay format, it is necessary to consider that this device should have the smallest possible size and, depending on the scale, in some cases the accomplishment of studies of microfluidies is demanded.

The technology of micro-fluids aims, in a general sense, to improve the analytical performance of sensors through the reduction of reagent consumption, the decrease of the time of analysis and the increase of the reliability and of the sensibility, all this by means of the automation and integration of multiple processes in only one device. Several designs using technology of microfluids applied to immunoassays were developed (Wang $\mathrm{H}$. et al., 2008; Dong et al., 2007; Tang et al., 2007). Bange et al. (2005) indicate and discuss in full detail other fundamental aspects that should be considered for all the devices accomplishing immunoassays, such as: (a) type of micro-fluid; (b) electrode surface modification in order to prevent the adsorption of the sample and the key reagents, which can degrade the assay performance; (c) detection device adaptation: the systems of detection of assays for different signal transducers, which recognize the event of the $\mathrm{Ab}-\mathrm{Ag}$ linking, should be adapted to very small volumes.

All these aspects show that immunosensor improvement is a topic of optimization applied to Biochemical Engineering, whose variables are: sensitivity enhancement and decrease of the smallest detection limit, time of analysis decrease, simplification of the analysis procedure (fewer stages), miniaturization of the equipments and automation of the measurement procedures.

\section{CONFIGURATIONS OF TRANSDUCERS}

The transducer selection depends on the physical-chemical changes of the specific reaction that happens in the bio-layer. According to the transducer used, immunosensors can be classified as electrochemical (potentiometric, amperometric and conductometric), optical (luminescence measurement, fluorescence, ellipsiometry etc.) and piezoelectric - mass detectors (they relate the oscillation frequency of piezoelectric crystals with mass variation). Each immunosensor is designed and optimized for a function under defined conditions, related to a specific problem, which involves considerations related to sensitivity, speed, efficiency and simplicity of the assay procedures. The greatest problem is to reproduce the obtained results, especially depending on the technique and on the analytical range.

Several immunosensor configurations are presented in Figure 3. Note that the bioreceptor molecules are immobilized on an appropriate matrix in order to form a bio-layer in the exposed surface of the transducer. Transducers that use ion-selective electrodes and Field Effect Transistors (FET) belong to the category of potentiometric transducers; surface plasma detectors and surface acoustic wave detectors belong to the category of piezoelectric transducers. Potentiometric transducers, together with conductive and amperometric sensors, belong to the category of electrochemical transducers. The construction materials for transducers are also presented in Figure 3. 


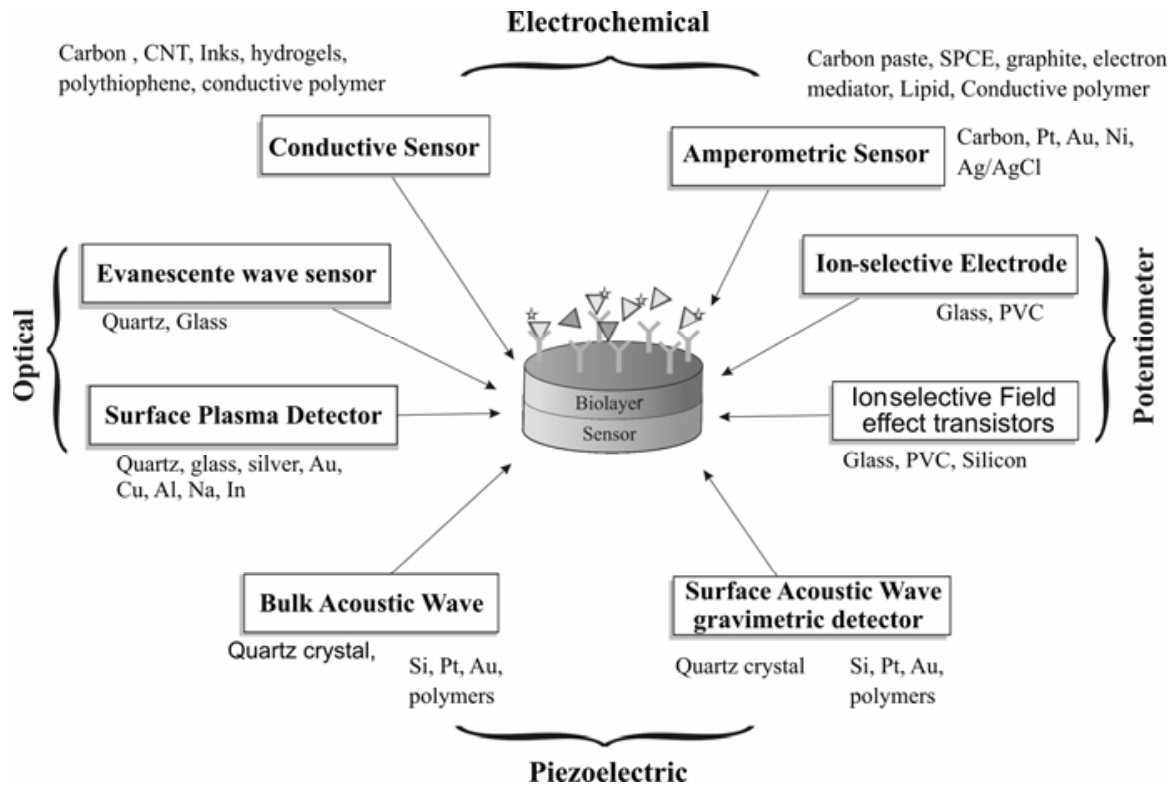

Figure 3: Various Immunosensor configurations

Immunosensors of wider use are currently those which contain electrochemical detection elements, such as physical transducers. These detecting elements can be subdivided into potentiometric (field effect transistors and ion-selective electrodes) and amperometric detectors (graphite electrodes or noble metal electrodes, such as gold or platinum); the last ones measure the current for a certain potential constant or variable. The popularity of these electrochemical immunosensors is due not only to their high sensitivity and selectivity, appropriate for immunoassays, but also because, in comparative terms, these instruments are indeed cheaper and it is possible to miniaturize them. Moreover, the continuous response of the sensor system allows computerized control, simplifying the electrochemical detection, bio-security and lower cost than other analytical techniques.

Piezoelectric immunosensors and Quartz Crystal Microgravimetric (QCM) immunosensors have also been object of research. These immunosensors determine the mass variation due to the formation of an immune $\mathrm{Ab}-\mathrm{Ag}$ complex on the surface of a piezoelectric crystal, used as detector.

The optical immunosensors are also objects of study, although their practical use is presently limited due to the high costs of instrumentation, the sophistication of preparation procedures and the necessity of highly qualified personnel.

\section{Electrochemical Immunosensors}

This kind of sensor uses the bio-recognition element linked with electrochemical transducers.
This means that the biological recognition is measured by means of an electrochemical signal. The electrodes employed can be easily miniaturized and, due to the advanced technology of semiconductors and serigraphy, they can be mass-produced. These characteristics have made possible great development in the area of biosensors, as corroborated by the number of publications and patents. Inside the group of electrochemical immunosensors, it is possible to classify them in three groups: Amperometric, Potentiometric and Impedimetric and Conductometric. The amperometric ones are the most used (Mehrvar et al., 2004).

Electrochemical transducers have a very important role in environmental protection. Particularly, electrochemical sensors and detectors are interesting because of the advantages of their technology, which include economy, portability and the possibility of directly identifying and quantifying specific compounds in complex mixtures, commonly found in air, soil and water and in biological samples (Stradiotto et al., 2003; Erdem et al., 2000). Such devices satisfy many of the demands for environmental analysis, and they are inherently sensitive and selective for electroactive species. They are also fast, precise and have a low cost (Chen et al., 2006; Mehrvar et al., 2004; Richards et al., 2002).

\section{Amperometric Immunosensors}

The interconnection of voltammetric principles with immunologic reactions makes it possible to develop low cost, highly sensitive, and selective 
analytic devices - the amperometric immunosensors. Amperometry is a dynamic process in which the electron flow to an inert electrode is measured, typically maintaining a constant applied potential in order to drive the electron flow to or from the monitored redox molecule. The fundamental system of measurement uses three electrodes: a working electrode where the desired reaction takes place; a reference electrode which governs the potential value applied to this working electrode, and a counterelectrode which carries the current flow away from the reference electrode.

In principle, two electrodes would be enough the working electrode and the reference electrode. The potential is applied to the electrochemical cell and then the current is registered as a function of this potential. However, some disadvantages arise in this system. As the reference electrode carries current, the electrode will polarize and will result in an over potential. This fact induces an unknown potential on the working electrode and it leads to inexact measures in sensitive systems. Another disadvantage of the two electrode system is the inaccuracy caused by the consumption of the reference electrode. These problems can be overcome by using larger reference electrodes. This is not a feasible option when the portability or the miniaturization of the system is desired or needed.

The best solution for these problems involves the use of a three-electrode system. In a three-electrode system, besides the working electrode and the reference electrode, a counter-electrode is introduced. This gives a true reference electrode in order to control the potential and a counter-electrode for current injection, which results in a more precise system when it is operated with high sensitivity levels. Figure 4 presents some proposals of amperometric immunosensor prototypes. It is probable that the choice of applied potential voltage is also influenced by the interference of the sample background (other redox species) and the detection limit that needs to be reached. For clinical samples it is usually necessary to work with oxidation potentials instead of reduction potentials, with the subsequent degasification of the sample to avoid the interference of oxygen that can be omnipresent and is a reducible species. The electrochemical detection of the label has several advantages, among which the fact of the system can operate with a comparable sensitivity in a cloudy solution. A greater use of the immobilized immune-agents can be reached mainly by the increase of the effective area of the solid support.

Amperometric immunosensors combine the advantages of the electrode process (high sensitiviy, linear relation of concentration-signal and selectivity due to the operation at different potentials) and the high specificity of immunologic reactions. The operation principle of amperometric immunosensors consists of the determination of the concentration gradient of an electroactive product of an enzymatic reaction or the determination of a variation in the concentration of an electrochemically active label.

Electrodes commonly used are built from conductive materials (noble metals such as gold or platinum, graphite, carbon paste, carbon nanotubes and vitreous carbon) or from polymeric conductors. In preparing the paste as conductive support, the conductive material is mixed with non-conductive liquid components (agglutinant) insoluble in water (mineral oil, silicon or paraffin oil) or rigid composite matrices (epoxy, silicon, Teflon, solid paraffin). The support matrixes which contain an agglutinative liquid agent are known as carbon paste (CP). These matrixes have been widely used as transducers in immunosensor development because they are cheap and their regeneration is possible. One of the components of the Ab-Ag complex is present in these supports, immobilized by different methods. The maximum content of this component should never exceed $10 \%$ by volume (usually $5 \%$ $[\mathrm{w} / \mathrm{w}]$ of the protein carried in the matrix). High amounts of protein reduce the conductivity and the stability of the electrode material. The protein is usually incorporated into the matrix in a lyophilized way, in other words, of hydrophilic nature. A high amount of this component can induce phenomena of swell and fluctuation of the background current, with concomitant erosion of the electrode surface.

The immobilization of the protein by using carbon paste electrode (CPE) is attractive by its extreme simplicity; the paste can be prepared with a spatula through the mixture of different components. A very important factor for a good reproducibility of the assays is the homogenization of the paste. When preparing the modified CPE, the mixture procedure should be carefully controlled (Kutner et al., 1998). Another advantage of the CPE in comparison with other solid electrodes is its regeneration. The electrode surface can simply be regenerated, after some assays, by only removing the corroded or used layer and polishing the surface, since the volume of the paste serves as a protein reservoir (Shan et al., 2002). The behavior of CPE modified with peroxidase (HRP-CPE) using several kinds of commercial graphite powders and certain additive elements known to act as promoters or stabilizers has been investigated by many investigators. One of the first works was presented by Popescu et al. (1995). They also studied the conditions of the enzyme immobilization (linking by adsorption or covalent for different $\mathrm{pH}$ values). Graphite powder has been widely used in the preparation of this paste (Majid et al., 2003; Zhou et al., 2002; Dursun et al., 2003; Sarkar et al., 1999) and it has been preferred due to its low cost. 


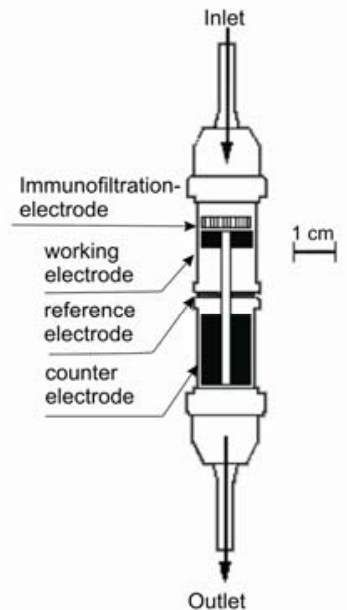

Schematic of the flow-injection immunosensor. Adapted from Abdel-Hamid et al., 1999.

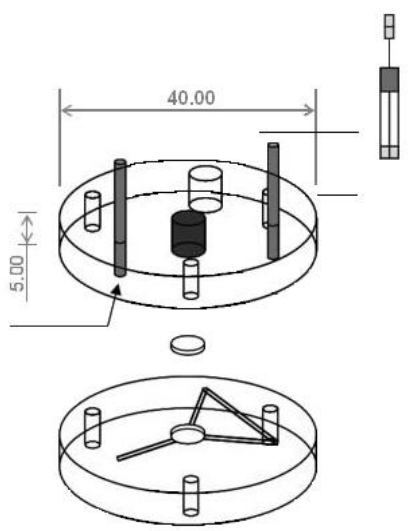

Schematic representation of components in the amperometric cell. Adapted from Salinas et al., 2005.

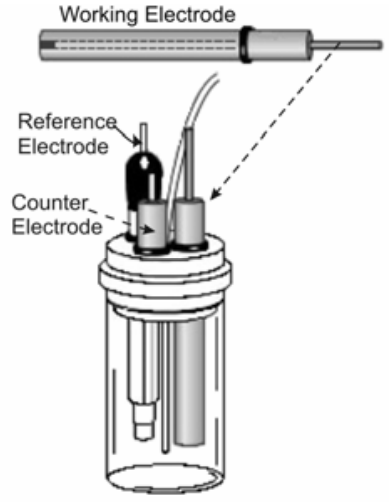

Schematic of Amperometric cell with general configuration of amperometric immunosensor. (Bojorge et al., 2007)

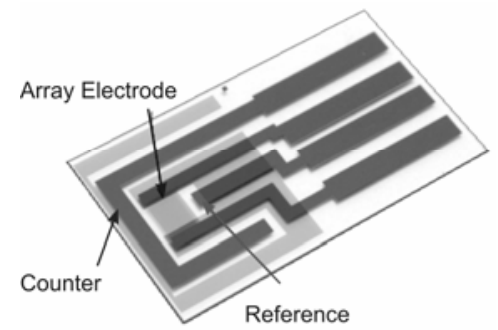

Schematic layout of the SPCE. Adapted from Darain et al., 2003.

Figure 4: Different prototype design of amperometric immunosensors proposed in the literature

Another immunosensor modality considers the use of screen-printed carbon electrode (SPCE), Two techniques borrowed from the electronics industry have proved particularly important--screen printing (ink is pressed through a mask to form a pattern on a ceramic or plastic base) and photolithography (a photoresistant material is exposed to ultraviolet light passed through a mask and then the silicon is chemically etched). Reproducible manufacture of biosensors with screen printing techniques means that each instrument does not have to be calibrated before use. In this modality, Sarkar et al. (1999) developed an electrode immunosensor of the SPCE type without mediator, covered by a conductive polymer $\left(5.2^{\prime}: 5^{\prime} 2^{\prime \prime}\right.$ terthiophene-3-carboxylic acid) for the detection of rabbit IgG as analyte. Horseradish peroxidase (HRP) and streptavidin were covalently linked with the polymer in the electrode and the biotinylated antibody was immobilized on the electrode surface using
Avidin/Biotin coupling. Stiene et al. (2002) described a screen-printed flow-through cell for immunoanalysis, which allows determining the activity of the peroxidase by means of the electrochemical reduction of pbenzoquinone. The advantage of using SPCE is that it offers the possibility of low cost production, without needing any additional mechanical part. It facilitates miniaturizing, since the detector works as a fine layer detector with very small internal volumes (usually $<1$ $\mathrm{mL}$ ). The carbon or graphite paste or screen printing techniques are frequently used in preparing electrodes for immunosensors.

Several methodologies conventionally applied in immunoassays have been used in amperometric immunosensors, although the heterogeneous methods stand out because of their widest application. They are characterized by the need of accomplishing a physical separation of the formed immunocomplex and the non-linked species. 
The use of highly dispersed carbon material for developing amperometric immunoassays by flow has also been reported. Abdel-Hamid et al. (1998) developed an immunoassay system for flow based on an amperometric immunosensor which uses a highly dispersed conductive immunosorbent. The size of carbon particles (thousands of $\AA$ ) is comparable to the size of protein molecules. This results in a pseudohomogeneous immunointeraction among the free and immobilized immunespecies. The system demonstrated a low detection limit ranging from $10^{-11} \mathrm{M}$ (for Rabbit $\mathrm{IgG}$ ) and the total assay time was only $17 \mathrm{~min}$. Table 2 presents some analytical characteristics, usually used in amperometric immunosensor systems.

Table 2: Analytic characteristics of immunoassays and amperometric transducers

\begin{tabular}{|c|c|c|c|c|c|c|c|c|c|}
\hline Analyte & Assay & Electrode $\left(\mathrm{E}^{0}\right)$ & Immobilization & Marker & \multicolumn{2}{|c|}{$\begin{array}{c}\text { Range/Limit of } \\
\text { detection }\end{array}$} & $\begin{array}{c}\text { Time of } \\
\text { detection }\end{array}$ & Sample & Reference \\
\hline Clenbuterol & ELISA & GCE MWCNTs & Covalent & Redox (free) & \multicolumn{2}{|l|}{$0.32 \mathrm{ng} \mathrm{mL}^{-1}$} & $40 \mathrm{~min}$ & Buffer & He P. et al., 2009 \\
\hline Lactoferrin & Competitive & Iodide & Adsortion & BAC-SulfoNHS & \multicolumn{2}{|l|}{$35 \mathrm{nM}$} & $5 \mathrm{~min}$ & Milk & Campanella et al.2008 \\
\hline Okadaic acid & ciELISA & SPEs & Adsorption & ALP/ HRP & \multicolumn{2}{|c|}{1.07 and $1.98 \mu \mathrm{gL}^{-1}$} & $30 \mathrm{~min}$ & Shellfish & Campàs et al.2008 \\
\hline $\begin{array}{l}\text { Staphylococcus } \\
\text { aureus }\end{array}$ & Competitive & $\begin{array}{l}\text { Au SPEs: } 0.00 \mathrm{~V} \\
\text { (vs. } \mathrm{Ag} / \mathrm{AgCl} \text { ) }\end{array}$ & Covalent & HRP-antiRbIgG & \multicolumn{2}{|c|}{$\begin{array}{l}1.3 \times 10^{3}-7.6 \times 10^{4} \\
\text { cellsmL } \\
\left(1.4 \times 10^{4} \text { cellsmL }^{-1}\right)\end{array}$} & $30 \mathrm{~min}$ & Milk & $\begin{array}{l}\text { Escamilla-Gómez et } \\
\text { al. } 2008\end{array}$ \\
\hline hIgG & Sandwich & $\begin{array}{l}\text { Pt nanoparticle: } \\
-1.2-0 \mathrm{~V}\end{array}$ & Adsorption & ALP & \multicolumn{2}{|c|}{$\begin{array}{l}10 \mathrm{pgmL}^{-1}-1.0 \\
\mu \mathrm{gmL}^{-1}\end{array}$} & $10 \mathrm{~min}$ & $\begin{array}{l}\text { PBS/ } \\
\text { Serum }\end{array}$ & Huang et al., 2008 \\
\hline CEA & --- & $\begin{array}{l}\text { GCE-DNA-PDDA: } \\
-0.6 \text { to } 0.2 \text { (vs. SCE) }\end{array}$ & Adsorption & --- & \multicolumn{2}{|c|}{$\begin{array}{l}0.5-120.0 \mathrm{ngml}^{-1} \\
\left(0.3 \mathrm{ng} \mathrm{ml}^{-1}\right)\end{array}$} & -- & Buffer & Li et al., 2008 \\
\hline$\alpha$-fetoprotein & Competitive & Au-wires & Covalent & HRP-anti-CEA & \multicolumn{2}{|l|}{---} & $35 \mathrm{~min}$. & Serum & Wang et al., 2008 \\
\hline Progesterone & Competitive & $\begin{array}{l}\text { Tyr-Aucoll- } \\
\text { graphite-Teflon }\end{array}$ & Adsorption & ALP-prog & \multicolumn{2}{|l|}{$0.43 \mathrm{ngmL}^{-1}$} & --- & Milk & Carralero et al., 2007 \\
\hline Probarley lectin & ELISA & $\begin{array}{l}\mathrm{Pt}((-300 \mathrm{mV} \text { vs } \\
\mathrm{Ag} / \text { Agul })\end{array}$ & Covalent & $\mathrm{mAb}-\mathrm{HRP}$ & \multicolumn{2}{|c|}{$\begin{array}{l}10^{-3}-10^{2} \mu \mathrm{gmL}^{-1} \\
\left(10^{-3} \mu \mathrm{gmL}^{-1}\right)\end{array}$} & --- & Buffer & Sadik et al., 2007 \\
\hline $\mathrm{SjAb}$ & Indirect & GCE & Adsorption & Colloidal gold & \multicolumn{2}{|c|}{\begin{tabular}{|l}
6.4 ng. $\mathrm{ml}^{-1}-100$ \\
$\mu \mathrm{g} \cdot \mathrm{ml}^{-1}\left(3.0\right.$ ng. $\left.\mathrm{ml}^{1}\right)$ \\
\end{tabular}} & $60 \min$ & Buffer & Chu et al., 2005 \\
\hline anti-CT & Sandwich & Pt or GCE & Covalent & $\begin{array}{l}\text { HRP- rabbit } \\
\text { IgG }\end{array}$ & \multicolumn{2}{|l|}{$50{\mathrm{ng} . \mathrm{ml}^{-1}}^{-1}$} & --- & Buffer & Ionescu et al., 2005 \\
\hline $\begin{array}{l}\text { Ab Salmonella } \\
\text { typhi }\end{array}$ & Indirect & $\begin{array}{l}\text { SPCE ( } 0.40 \mathrm{~V} \text { vs } \\
\mathrm{Ag} / \mathrm{AgCl})\end{array}$ & Adsorption & Apt & \multicolumn{2}{|l|}{--- } & --- & Serum & Rao et al., 2005 \\
\hline $\begin{array}{l}\text { Salivary } \\
\text { amylase } \\
\text { proteins }\end{array}$ & ELISA & Au-electrode & Covalent & --- & \multicolumn{2}{|l|}{$1.57 \mathrm{pg} . \mathrm{ml}^{-1}$} & --- & Buffer & Aluoch et al., 2005 \\
\hline $\mathrm{HCG}$ & Competitive & GCE & Adsorption & HRP-anti-HCG & \multicolumn{2}{|l|}{1.4 mIU.ml ${ }^{-1}$} & --- & Serum & Chen et al., 2004 \\
\hline $\mathrm{HCS}$ & Competitive & SPCE & Adsorption & GOx e HRP & \multicolumn{2}{|l|}{$0.01-1 \mathrm{ng} \mathrm{ml}^{-1}$} & $15 \mathrm{~min}$ & Buffer & Dzantiev et al., 2004 \\
\hline rabbit $\mathrm{IgG} \mathrm{Ag}$ & --- & $\begin{array}{l}\mathrm{GCE}(-0.2 \&+0.4 \mathrm{~V} \\
\text { vs. } \mathrm{Ag} / \mathrm{AgCl})\end{array}$ & Entrapment & label-free & \multicolumn{2}{|l|}{---} & $200 \mathrm{~ms}$ & Buffer & Gooding et al., 2004 \\
\hline $\mathrm{SjAg}$ & Competitive & CPE & Entrapment & $\mathrm{SjAg}-\mathrm{HRP}$ & \multicolumn{2}{|c|}{$\begin{array}{l}0.11-22.4 \mathrm{mg} \mathrm{ml}^{-1} \\
\left(0.06 \mathrm{mg} \mathrm{ml}^{-1}\right)\end{array}$} & --- & Buffer & Lei et al., 2004 \\
\hline mouse IgG & Sandwich & GCE & Adsorption & Apt & \multicolumn{2}{|c|}{$0.01-100 \mathrm{mg} \mathrm{ml}^{-1}$} & --- & Buffer & Másson et al., 2004 \\
\hline rabbit IgG & Competitive & SPCE & Covalent & Gox & \multicolumn{2}{|c|}{$\begin{array}{l}0.5-2 \text { mg.ml } \mathrm{ml}^{-1} \\
\left(0.33 \mathrm{mg} \cdot \mathrm{ml}^{-1}\right) \\
\end{array}$} & --- & Buffer & Darain et al.2003 \\
\hline $\mathrm{C} 3$ & Competitive & $\begin{array}{l}\mathrm{GCE}(100 \mathrm{mV}, \\
\mathrm{Ag} / \mathrm{AgCl})\end{array}$ & Adsorption & HRP-C3 & \multicolumn{2}{|l|}{$2.4 \mathrm{ng} \cdot \mathrm{mL}^{-1}$} & $30 \mathrm{~min}$ & Serum & Zhou et al., 2003a \\
\hline $\mathrm{Sj} \mathrm{Ab}$ & Competitive & $\begin{array}{l}\mathrm{GCE}-250 \mathrm{mV} \\
(\mathrm{Ag} / \mathrm{AgCl})\end{array}$ & Adsorption & HRP-SjAb & \multicolumn{2}{|c|}{$0.05-4,8 \mathrm{mg} \cdot \mathrm{ml}^{-1}$} & ---- & Buffer & Zhou et al., 2003b \\
\hline Sea food toxins & Competitive & $\begin{array}{l}\text { SPCE }(+300 \mathrm{mV} \text { vs. } \\
\mathrm{Ag} / \mathrm{AgCl})\end{array}$ & --- & Apt & \multicolumn{2}{|c|}{$10-160 \mathrm{ppb}(2 \mathrm{ppb})$} & $35 \mathrm{~min}$ & Buffer & Kreuzer et al., 2002 \\
\hline $\mathrm{Sj} \mathrm{Ag}$ & Competitive & $\begin{array}{l}\text { GCE - SjAb: } \\
0.1 \mathrm{~V}(\mathrm{Ag} / \mathrm{AgCl})\end{array}$ & Adsorption & HRP-SjAg & \multicolumn{2}{|c|}{$0.5-30 \mathrm{mg} \cdot \mathrm{ml}^{-1}$} & $30 \mathrm{~min}$ & Buffer & Zhou et al., 2002 \\
\hline \multicolumn{10}{|l|}{ Legends } \\
\hline \multicolumn{2}{|l|}{$\mathrm{Ab}$, antibody } & \multicolumn{2}{|l|}{ C3: complement III } & \multicolumn{4}{|c|}{ GOx: Glucose oxidase } & in $\mathrm{G}$ & \\
\hline \multicolumn{2}{|l|}{ Ag, antigen } & $\mathrm{E}^{0}$ : Potential & & CPE : Carbon pa & ste Electrode & CEA : & carcinoemb & yonic antigen & \\
\hline $\begin{array}{l}\text { HCS: herbici } \\
\text { chlorsulfuror }\end{array}$ & & HCG: chorionic gon & ladotrophin & $\begin{array}{l}\text { ELISA: enzyme- } \\
\text { immunosorbent }\end{array}$ & $\begin{array}{l}\text {-linked } \\
\text { assay }\end{array}$ & $\begin{array}{l}\text { SPCE } \\
\text { electr }\end{array}$ & $\begin{array}{l}\text { : screen-pri } \\
\text { des }\end{array}$ & ed carbon & \\
\hline $\mathrm{Pt}:$ platinum & electrode & FIA: Flow Injection & Analyze & $\begin{array}{l}\text { MWCNTs: mult } \\
\text { nanotubes }\end{array}$ & i-wall carbon & SPEs: & screen-prin & d electrodes & \\
\hline $\begin{array}{l}\text { GCE: Glassy } \\
\text { Electrode }\end{array}$ & Carbon & $\begin{array}{l}\text { PDDA::Poly - } \\
\text { diallyldimethylamm } \\
\text { chloride }\end{array}$ & onium & HRP: horseradis & $\mathrm{h}$ peroxidase & & & & \\
\hline $\begin{array}{l}\text { GCE: Glassy } \\
\text { Electrode }\end{array}$ & Carbon & $\begin{array}{l}\text { PDDA::Poly - } \\
\text { diallyldimethylamm } \\
\text { chloride }\end{array}$ & onium & ALP: alkaline ph & osphatase & & & & \\
\hline
\end{tabular}




\section{Piezoelectric Immunosensors}

The piezoelectric transducer allows a binding event to be converted into a measurable signal, for example resonance frequency changes. The principle is based on the piezoelectric properties of some materials such as quartz crystals. The interest in studies of immunologic reactions using quartz crystals as transducers had significant growth in the last years (Babacan et al., 2000; Shen et al., 2005; Skládal et al., 2003; Su et al., 2000; Le D. et al., 1995). In the same way as the optical methods, they allow, in principle, the direct detection of the Ag-Ab reaction, without need of labels.

The piezoelectric crystals are those that enter in resonance by the application of an external alternate electric field, which results in a mechanical deformation of them with the generation of guided dipoles and electric voltage. The oscillation frequency is determined by the crystal mass. The linking of antibodies to these surfaces allows the immunosensors construction, which can directly detect the connection with their corresponding analyte. The piezoelectric immunosensors can adopt two different ways of detection. In the first, called Bulk Acoustic Wave (BAW), the resonance happens in the whole crystal mass. They are also called Quartz Micro Balance (QMBs) due to their mass sensitivity. They usually operate in a frequency ranging from 10 to $30 \mathrm{MHz}$. If an antibody is immobilized in its surface and the interaction with its corresponding antigen occurs, the resonance frequency reduces according to the Sauerbrey equation:

$\Delta \mathrm{f}=-2.3 \times 10^{6} \mathrm{f}^{2} \frac{\Delta \mathrm{m}}{\mathrm{A}}$ where $\mathrm{f}$ is the oscillation frequency in $\mathrm{Hz}, \mathrm{m}$ is the adsorbed mass in $\mathrm{g}$, and $\mathrm{A}$ is the sensitive area in $\mathrm{cm}^{2}$. In the second way of detection, the Surface Acoustic Wave (SAW) is prominent and the resonance happens only in the crystal surface. The mass increase which results from the affinity reaction implies a change in the wave speed in the acoustic path between two pairs of electrodes and, therefore, in the oscillation frequency, which usually operates at frequencies higher than QMBs.

Several anisotropic crystals exhibit the piezoelectric effect, with the generation of oriented dipoles and electric voltage. Inversely, the alternating voltage applied in such crystals excites vibrations. The resonance frequency, equal to the natural vibration frequency, which transfers energy from the electric field to the crystal, is very efficient and the residual energy is conserved in the oscillating system. A typical piezoelectric quartz crystal is shown in Figure 5, together with a scheme of a horizontal vibration cut. A thin quartz plate (AT-cut) is covered with metal on both sides of the plate.

One of the advantages of the piezoelectric immunosensors is the possibility of directly monitoring a wide range of the analyte in an immunoreaction, without the need of using labels or reagents. However, piezoelectric immunosensors impose antibody specificity as a strict demand, because cross reactions cause significant interferences. A non-specific binding of the reaction medium components to the crystal surface can also happen. When non-specific binding is taken into account, the determination errors are relatively low.

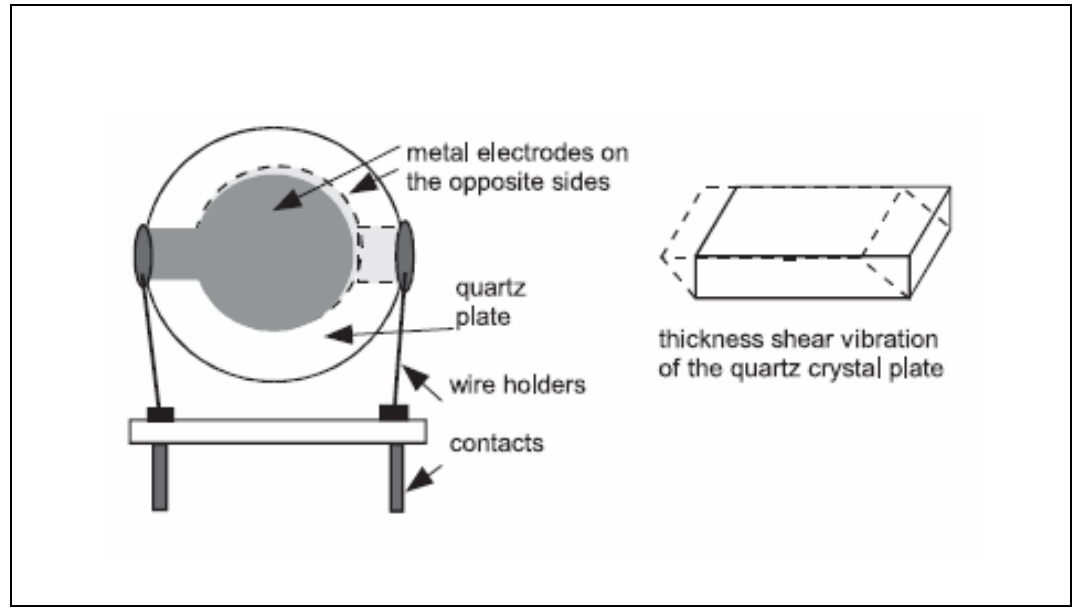

Figure 5: Piezoelectric quartz crystal microbalance and scheme of vibration. Adapted from Skláda P. (2003) 


\section{Optical Immunosensors}

The first optical immunosensors were developed by using optical fiber, due to its flexibility and low cost. These immunosensors consist of an optic fiber through which the electromagnetic wave propagates. At the end of the optical fiber there is a sensorial layer which is appropriate to the electromagnetic radiation that goes through the fiber by means of a phenomenon known as total internal refraction (IR). In this way, the interactions between the electromagnetic radiation and the compositions labels bonded to the immunoreagents allow detecting of affinity reactions via, for example, variations in fluorescence, absorbance or polarization.

The optical immunosensors can be subdivided into three main groups (Leung et al., 2007; D'Orazio, 2003; Jacobson, 1998). The first group consists of sensors based on the direct monitoring (without labels) of an immune reaction. The second group includes optical sensors which detect marked compounds (with a fluorescent label or other one) of an immune reaction. The third group consists of sensors that detect the colored product of an enzymatic reaction with the use of labeled-enzyme. When a fluorescent detection is used, the detector is usually positioned sequentially to the immunoreactor. The different immobilisation supports and the labeled enzymes used for the previous electrochemical immunosensor type could be used for the optical systems. Nevertheless, the reactions involved during the detection will be different.

Some advantages of the optical immunosensors in relation to the electrochemical immunosensors indicated by several researchers are the insensitivity to electric interfaces and the high safety for in vivo studies. However, the use of optical immunosensores is less advantageous when compared with other techniques because of the time consumed in analysis, since they frequently require multiple stage assays. Moreover, problems associated with the lack of detection selectivity due to the non-specific adsorption and, fundamentally, the high cost of instruments, constitute other disadvantages, which limit their use in the field of detection (Fowler et al., 2008; Carnes and Wilkins, 2005; Morgan et al., 1996).

\section{CHARACTERISTIC PARAMETERS FOR COMPARATIVE ANALYSIS OF IMMUNOSENSORS}

An analysis of published data shows that the monitoring of compounds present in preparations of drugs, hormones and pathogens is important. For this reason, several immunosensors - different in their detection principles, in the use of labels, and in the analytical capacities - were proposed until now. Figure 6 presents an evolution of works on immunosensors in the last years. It is possible to observe that electrochemical immunosensors have a growing tendency in their application, followed by piezoelectric immunosensors and, with smaller application, optical immunosensors. Each immunosensor is projected for operating under specific conditions, which are more appropriate for special problems. In this case, several demands are established, for example, in sensitivity terms, speed, efficiency and simplicity of assays procedures.

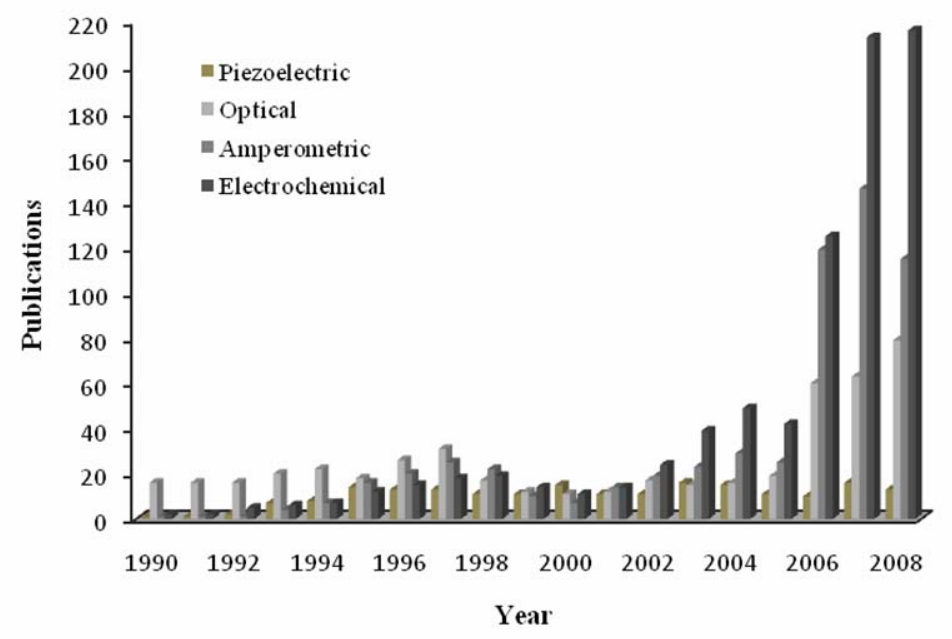

Figure 6: Comparative results on publications on Piezoelectric, Optical and Electrochemical immunosensors, being highlighted the interest and evolution of the amperometric ones (Source: Information collected and compiled in www.sciencedirect.com from 1990 to September 2008). 
Some comparison parameters in the development of immunosensors are sensibility, detection level, specificity and calibration.

The required sensitivity for a particular analyte is determined by the concentration levels found in the measurement medium of interest. For enzymatic biosensor measurements of glutamate, the difference between the extracellular milieus of $10 \mu \mathrm{M}$ and $10^{-10}$ $\mathrm{mM}$ for intracellular measurement is significant (Kahlert et al., 2004). The discrepancy between intra- and extra-cellular concentrations is not confined to analytes measured with amperometric immunosensors, but also to other important species such as oxygen with intra- and extra-cellular concentrations given respectively by $(0.032$ $\mathrm{mM} / 0.24 \mathrm{mM}), \mathrm{Na}+(20 \mathrm{mM} / 140 \mathrm{mM})$, and $\mathrm{K}+(5$ $\mathrm{mM} / 130 \mathrm{mM}$ ) (Kahlert et al., 2004). These differences create concentration gradients across the cell membrane, which may be changing rapidly in the second to millisecond time domain.

Immunosensor sensitivity can be enhanced by changing the surface of the electrode. For oxidation of peroxidase, which is most rapid on $\mathrm{Pt}$, carbon fibers can be platinized (Clark et al., 1998). Deposition of platinum black on carbon or $\mathrm{Pt}$ electrodes also increases the active surface area, further enhancing sensitivity. However, this strategy also increases the electrode sensitivity to electroactive interferences and makes the sensor vulnerable to decreased response resulting from adsorption of surface-active species. Special films can serve to concentrate analytes by adsorption, such as Nafion. The sensitivity of a SPR immunosensor for the detection of antigens with a very low concentration can be increased by control of the orientation of antibodies immobilized on the SPR sensor surface. When antibodies are immobilized on a solid surface, their activity is usually less than that of dispersed antibodies. The main reason for activity reduction is due to the random oriented array of the antibody molecules on the solid surface. Therefore, the development of the immobilization method for antibodies is strongly required to make an oriented layer.

Liang et al. (2005) developed a hepatitis B surface antigen (HBsAg) immunosensor by selfassembling gold nanoparticles to a thiol-containing sol-gel network. The amount of HBsAb immobilized on the electrode surface determines the sensitivity and the linear range of the immunosensor. The larger amount of HBsAb immobilized on the electrode surface can provide more immunoactive sites for the immunoreactions of antigen.
Amperometric immunosensors are based on the determination of the Ab-Ag interaction by use of an enzyme as marker. These enzymatic markers, peroxidase, alkaline phosphatase, laccase or glucose oxidase are commonly attached to a secondary antibody. After their immobilization, the enzymes catalyze the formation of electroactive species, which are amperometrically detected at the electrode surface, thus allowing the quantification of the immunoreactions. The sensitivity of such an approach obviously depends on the specific activity of the enzyme as well as on the electrochemical properties of the products of the enzyme reaction. In addition, the immunosensor performances are mainly a function of the accessibility to the electrode surface for the generated electroactive species. The latter point is controlled by the steric constraints due to the immobilization procedure of the immunoreagent used as probe and, hence, by the bulkiness of the diffusing species. Ionescu et al. (2005) compared the performances of amperometric immunosensors for cholera antitoxin based on three enzyme markers (HRP, biotinylated polyphenol-oxidase (PPO-B) and biotinylated glucose-oxidase (GOX-B)), which present an average standard deviation of the sensitivity around $450 \mathrm{nA} \mathrm{\mu g}^{-1} \mathrm{ml} \mathrm{cm}$.

A key problem in the use of immunosensors is the reproducibility of certain results. Depending on the detection technique and the analytical range, the determination of the error can vary over a wide range. Specifically, the use of optical immunosensors, for instance, based on SPR, is usually characterized by the low detection level and the smallest determination errors $(2-8 \%$ level $)$ through the whole analytical range. However, these immunosensors exhibit a narrower analytical range and they require the use of sophisticated and expensive instruments. Therefore, they are less common than the amperometric immunosensors. Shen et al. (2005) investigated the reproducibility of the piezoelectric quartz crystal immunosensor; 100 $\mathrm{mU} / \mathrm{ml}$ of antisperm antibody concentration was determined repeatedly under the optimized experiment conditions. The average frequency change of three parallel experiments is $170 \pm 11 \mathrm{~Hz}$, and the relative standard deviation (R.S.D.) is $6.65 \%$. At the same time, complex systems for amplification of signals (e.g., with use of enzymatic reactions) are more frequently used in amperometric immunosensors; they require the use of additional reagents and the course of the immunological reaction cannot be monitored directly. Moreover, amperometric immunosensors are characterized by a 
wide range of error determination, depending on the label used and the format of the immunoassay. More frequently, the error determination may vary from 2 to $20 \%$; however, it can be larger in specific cases.

As a consequence of the direct monitoring of the interaction between antigens and antibodies, piezoelectric immunosensors impose strict requirements on the antibodies' specificity, because any cross-linking can produce significant interferences. However, if non-specific linkings are taken into account, the determination errors with piezoelectric immunosensors are relatively low and they vary from $3-5$ to $10-15 \%$. In addition, some electronic filtering of background noise can be effective. Extending the linear range by creating diffusion-limiting barriers with permselective polymer membranes is a widely employed approach. The sensor response is no longer controlled by the kinetics of the enzyme reaction, but by mass transfer. This has the advantage of minimizing temperature effects (approximately $2.5 \% /{ }^{\circ} \mathrm{C}$ increase in the rate of mass transfer versus $\sim 10 \% /{ }^{\circ} \mathrm{C}$ for enzyme catalysis). The disadvantage is a decrease in sensitivity and response time and, under some conditions, complicated sensor response (Jablecki and Gough, 2000).

Assessment of sensor performance is critically dependent on a reliable procedure for calibration. It is frequently not possible to rely on in vitro calibrations as the basis for the in vivo performance. Much of the effort on calibration has been directed toward the performance of glucose sensors, where the basis for calibration is the assumption that the blood glucose concentration and the subcutaneous interstitial fluid yield the same value. This approach has been complicated by the fact that the ratio of blood/tissue glucose is not constant, but depends on a number of factors related to physiology of glucose and insulin (Wilson and Gifford et al., 2005). One of the disadvantages of the use of electrochemical sensors is the need of calibrating them before each measurement. In order to minimize the measurement uncertainty, it is necessary to have the same medium (for instance, $\mathrm{pH}$, ionic strength etc.) for the standard solution used for calibrating and for the sample. This is possible only for analysis in vitro. For analyses in vivo, the calibration method of the electrochemical sensor can significantly increase the measurement uncertainty, because the medium to be simulated consists of the organs or biological fluids which have to be measured (e.g., $\mathrm{pH}$, buffer type, acidity through the addition of $\mathrm{HCl}$ etc.) (Stefan et al., 2003). The determination of some ions, for instance $\mathrm{Na}+, \mathrm{K}+$,
Cl-, can create problems due to their presence in the buffer composition and in the electrolytic solution.

It is worthwhile to mention that the use of chemiometry is the key in order to minimize the uncertainty in data processing in all the analytical methods. With the growing sophistication of the instrumental techniques, more complex data treatments became necessary from a mathematical and statistical point of view, in order to relate the obtained signals (intensities for instance) with the desired results (concentrations). The statistical evaluation of analytic data plays a very important role in the minimization of the uncertainty of electrochemical sensors in clinical analyses. A good quantity of electrochemical sensors was proposed for clinical analysis. Lower uncertainties for the analytical information when an arrangement of electrochemical sensor is used in vitro and in vivo are obtained through the use of the best chemiometric methods for data processing. If the uncertainty of the simultaneous measurements of the compounds that use the electrochemical sensor arrangement is still big, it is possible to think of the application of electrochemical sensors/flow systems (e.g., flow injection analysis or sequential injection analysis) for a simultaneous assay of different components. This way the data processing can be made using simple statistical evaluation.

According to Kissinger (2005), in research applications, the economy in the sensor itself is less important than its application. For instance, if SPR helps in the development of a drug that will treat millions of people annually, the cost of the sensor will be very small compared to the benefit that can be reached. There are many examples, but it is necessary to be careful. Sensors are extraordinarily expensive when the cost of developing them exceeds the annual size of the market for the analyzed analyte. Cromatography, mass spectrometry and the immunoassay methods give better precision with lower limits of quantification for a wide variety of analytes. However, they present larger times of analysis and they don't make use of the advantages of miniaturization and portability of the instruments.

\section{CONCLUSIONS}

Immunosensors play an important role in the areas of health and environment because they provide powerful analytical tools for diagnosis, particularly when fast, low cost, and high sensitivity and specificity measurements are necessary. 
Advances in the area of immunosensors in commercial contexts can be accelerated by using modern instruments, besides signal processing methods such as chemiometry. It is possible to observe that bioengineering is paying increasing attention to the development of basic components and devices as a whole. Bioengineering will have a key role in this area in applying knowledge in order to improve sample data analysis and calibration. Immunosensor R\&D is highly multidisciplinary.

A range of molecules with bio-recognition properties can be used as bio-sensitive elements. A wide range of transducers is also available for creating new immunosensitive devices.

Nowadays, there is a great demand for the production of antibodies with association of desired antigen. However, it is necessary to overcome several challenges. The in vivo use of antibodies requires protein stability, as well as antigen affinity. The industrial scale production of antibodies is not yet massively accessible; additional advances in biochemical engineering technologies will be necessary. It is necessary that alternative immunoassays - i.e., using immunosensors - be easily adapted for the analysis of a wide analyte range, through the modification of antibodies used in the assay or by means of the employment of specific labels. However, micro and nanotechnology not only contribute to device miniaturization, but also contribute fundamentally to the development of modern principles of biosensitivity.

\section{ACKNOWLEDGEMENTS}

Financial support from Conselho Nacional de Desenvolvimento Científico e Tecnológico, $\mathrm{CNPq}$ (Proc. No. Proc: 473233/2007-0) and Fundação de Amparo à Pesquisa do Estado do Rio de Janeiro (Proc. No. E26/150.997/2006) are gratefully acknowledged. Also, we are thankful to Prof. Eveline Gomes Vasconcelos from the Department of Biochemical/ICB/UFJF for helpful discussion and cooperation to the immunoassays knowledge.

\section{REFERENCES}

Abdel-Hamid, I., Atanasov, P., Ghindilis, A. L., Wilkins, E., Development of a flow-through immunoassay system, Sens. Actuators B, 49, 202-210 (1998).

Abdel-Hamid, I., Ivnitski, D., Atanasov, P., Wilkins, E., Highly sensitive flow-injection immunoassay system for rapid detection of bacteria, Anal. Chim. Acta, 399, 99-108 (1999).

Adányi, N., Levkovets, I. A., Rodriguez-Gil, S., Ronald, A., Váradi, M., Szendrö, I., Development of immunosensor based on OWLS technique for determining Aflatoxin B1 and Ochratoxin A, Biosens. Bioelectron, 22, (6), 797-802 (2007).

Agui, L., Yanez-Sedeno P., Pingarron, J. M., Role of carbon nanotubes in electroanalytical chemistry: A review, Anal. Chim. Acta, 622, (1-2), 11-47 (2008).

Alocilja, E. C., Radke, S. M., Market analysis of biosensors for food safety, Biosens. Bioelectron. 18, (5-6), 841-846 (2003).

Aluoch, A. O., Sadik, O. A., Bedi, G., Development of an oral biosensor for salivary amylase using a monodispersed silver for signal amplification, Anal. Biochem., 340, (1), 136-144 (2005).

Babacan, S., Pivarnik, P., Letcher, S., Rand, A. G., Evaluation of antibody immobilization methods for piezoelectric biosensor application, Biosens.Bioelectron., 15, 615-621 (2000).

Bange, A., Halsall, H. B., Heineman, W. R., Microfluidic immunosensor systems, Biosens. Bioelectron., 20, (12), 2488-2503 (2005).

Bao, W., Strömblad, S., Use of an Immobilized Monoclonal Antibody to Examine Integrin $\alpha 5 \beta 1$ Signaling Independent of Cell Spreading, Biol. Proced., 4, (1), 81-87 (2002).

Bergveld, P., A critical evaluation of direct electrical protein detection methods, Biosens. Bioelectron., 6, (1), 55-72 (1991).

Bojorge-Ramirez, N. I., Medeiros Salgado, A., Valdman, B., Amperometric Immunosensor for Detecting Schistosoma mansoni Antibody, Assay and Drug Development Technologies, 5, (5), 673682 (2007).

Brahim, S., Wilson, A. M., Narinesingh, D., Iwuoha E., Guiseppi-Elie, A., Chemical and Biological Sensors Based on Electrochemical Detection Using Conducting Electroactive Polymers, Microchim. Acta, 143, 123-137 (2003).

Bratov, A., Ramón-Azcón, J., Abramova, N., Merlos, A., Adrian, J., Sánchez-Baeza, F., Marco, M. P., Domínguez, C., Three-dimensional interdigitated electrode array as a transducer for label-free biosensors, Biosens. Bioelectron., 24, (4), 729-735 (2008).

Briand, E., Salmain, M., Herry J-M, Perrot, H., Compère, C., Pradier, C. M., Building of an immunosensor: How can the composition and structure of the thiol attachment layer affect the immunosensor efficiency?, Biosens. Bioelectron., 22, (3), 440-448 (2006). 
Campanella, L., Martini, E., Tomassetti, M., New immunosensor for Lactoferrin determination in human milk and several pharmaceutical dairy milk products recommended for the unweaned diet, Journal of Pharmaceutical and Biomedical Analysis 48, 278-287 (2008).

Campàs, M., Iglesia, P., Berred, M., Kaned, M., Diogène, J., Martya, J. L., Enzymatic recycling based amperometric immunosensor for the ultrasensitive detection of okadaic acid in shellfish, Biosens. Bioelectron. 24, 716-722 (2008).

Cantarero, L. A., Butler, J. E., Osborne, J. W., The adsorptive characteristics of proteins for polystyrene and their significance in solid-phase immunoassays, Anal. Biochem., 105, (1), 375382 (1980).

Carnes, E., Wilkins, E., The Development of A New, Rapid, Amperometric Immunosensor for the Detection of Low Concentrations of Bacteria Part I: Design of the Detection System and Applications, American J. Applied Sci., 2, (3): 597-606, (2005).

Chen, G., Lin, Y. and Wang, J., Monitoring environmental pollutants by microchip capillary electrophoresis with electrochemical detection, Talanta, 68, 497-503 (2006).

Chen, J., Yan, F., Dai, Z., Ju, H., Reagentless amperometric immunosensor for human chorionic gonadotrophin based on direct electrochemistry of horseradish peroxidase, Biosens. Bioelectron., 21, 2, (15), 330-336 (2005).

Choi, M. M. F., Application of a long shelf-life biosensor for the analysis of 1-lactate in dairy products and serum samples, Food Chemistry 92(3), 575-581 (2005).

Chu, X, Xiang Z. F, Fu, X., Wang, S. P., Shen, G. L., Yu, R. Q., Silver-enhanced colloidal gold metalloimmunoassay for Schistosoma japonicum antibody detection, J. Immunol. Methods, 301, (1-2), 77-88 (2005).

Clark, C., Jr., Lyons, C., Electrode System for continuous monitoring in cardiovascular surgery, Ann. N. Y. Acad. Sci., 102, 29 (1962).

Clark, R. A., Zerby, S. E., Ewing, A. G., "Electrochemistry in Neuronal Microenvironments", In: Electroanalytical Chemistry, A. J. Bard and I. Rubinstein (Eds.), Vol. 20, pp. 227-294,Marcel Dekker, New York (1998).

Cooreman, P., Thoelen, R., Manca, J., vandeVen, M., Vermeeren, V., Michiels, L., Ameloot, M., Wagner, P., Impedimetric immunosensors based on the conjugated polymer PPV, Biosens. Bioelectron., 20, (10), 2151-2156 (2005).
Curulli, A., Valentini, F., Orlanducci, S., Terranova, M. L., Paoletti, C., Palleschi, G., Electrosynthesis of non conventional-polymer nanotubules: a new nanostructured material for analytical applications, Sens. Actuators, B: Chemical, 100, (1-2), 65-71 (2004).

D’Amico, A., Di Natale, C., Martinelli, E., Sandro, L., Baccarani, G., Sensors small and numerous: always a winning strategy? Sens. Actuators, B: Chemical, 106, (1), 29, 144-152 (2005).

Darain, F., Park, S. U., Shim, Y. B., Disposable amperometric immunosensor system for rabbit IgG using a conducting polymer modified screenprinted electrode, Biosens. Bioelectron., 18, 773-780 (2003).

Divya, P. S., Savitri, D., Mitra, C. K., Covalent enzyme immobilization onto glassy carbon matrix-implication in biosensor design, Biosci., 23, (2), 131-136 (1998).

Dong, H., Li, C. M., Zhang, Y. F., Cao, X. D., and Ye Gan, Screen-printed microfluidic device for electrochemical immunoassay, Lab Chip, 7, 1752 -1758 (2007).

D'Orazio, P., Biosensors in clinical chemistry, Clin. Chim. Acta, 334, (1-2), 41-69 (2003).

Dursun, Z., Sahbaz, Ì., Ertas, F. N., Nisli, G., Voltammetric and Flow Injection Amperometric Determination of Cysteine at a Glassy Carbon Electrode in the Presence of Copper(II) Ions, Turk J Chem., 27, 513-519 (2003).

Dzantiev, B. B., Yazynina, E. V., Zherdev, A. V., Plekhanova, Yu. V., Reshetilov, A. N., Chang, S. C., McNeil, C. J., Determination of the herbicide chlorsulfuron by amperometric sensor based on separation-free bienzyme immunoassay, Sens. Actuators, B: Chemical, 98, (2-3), 15, 254-261 (2004).

Erdem, A., Pabuccuoúlu, A., Merüc, B., Kerman, K., Özsöz, M., Electrochemical Biosensor Based on Horseradish Peroxidase for the Determination of Oxidizable Drugs, Turk J Med Sci, 30, 349-354 (2000).

Escamilla-Gómez, V., Campuzano, S., Pedrero, M., Pingarrón, J. M., Electrochemical immunosensor designs for the determination of Staphylococcus aureus using 3,3-dithiodipropionic acid di(Nsuccinimidyl ester)-modified gold electrodes, Talanta 77, 876-881 (2008).

Farré, M., Kantiani L., Barcelo, D., Advances in immunochemical, technologies for analysis of organic pollutants in the environment, Trends in Analytical Chemistry, 26, 7, 1100-1112 (2007).

Feng, K., Kang, Y. Zhao, J.-J., Liu Y-L, Jiang, J-H, Shen, G-L, Yu, R-Q, Electrochemical 
immunosensor with aptamer-based enzymatic amplification, Anal. Biochem. 378, 38-42 (2008).

Fernández-Sánchez, C., González-Garcia, A., CostaGarcia, A., AC voltammetric carbon paste enzyme immunosensors, Biosens. Bioelectron, 14, 917-924 (2000).

Fowler, J. M., Wong, D. K. Y., Halsall, H. B., Heineman, W. R., Recent developments in electrochemical immunoassays and immunosensors, in "Electrochemical Sensors, Biosensors and their Biomedical Applications", Xueji Zhang, Huangxian Ju, Joseph Wang (eds.), 115-143 (2008).

Gaag, van der B., Spath, S., Dietrich, H., Stigter, E., Boonzaaijer, G., Osenbruggen, T., Koopal, K., Biosensors and multiple mycotoxin analysis, Food Control, 14, 251-254 (2003).

Ghindilis, A. L., Atanasov, P.,Wilkinst, M., Wilkins, E., Immunosensors: electrochemical sensing and other engineering approaches, Biosens. Bioelectron., 13, (1), 113-131 (1998).

Ghindilis, A. L, Atanasov, P., Wilkins, E., Enzymecatalyzed direct electron transfer: fundamentals and analytical applications, Electroanalysis, 9, 661-674 (1997).

González-Martínez, M. A., Penalva, J., RodríguezUrbis, J. C., Brunet, E., Maquieira A., Puchades R., Immunosensors for pollutants working in organic media. Study of performances of different tracers with luminescent detection, Anal. Bioanal. Chem. 384, 1540-1547 (2006).

Gooding, J. J., Wasiowych, C., Barnett, D., Hibbert, D. B., Barisci, J. N., Wallace, G. G., Electrochemical modulation of antigen-antibody binding, Biosens. Bioelectron. 20, 260-268 (2004).

Gosling, J. P., Enzyme immunoassay: with and without separation, in Principles and practice of immunoassay, 2nd [rev.] Ed., C. P. Price and D. J. Newman, Eds., Stockton Press:London. 349, 351-388 (1997).

Harlow, E., Lane, D., In: Antibodies: A laboratory Manual. CRC Press, Cold Spring Harbor, New York, 553 (1988).

He, P., Wang, Z., Zhang, L., Yang, W., Development of a label-free electrochemical immunosensor based on carbon nanotube for rapid determination of clenbuterol, Food Chemistry, 112, 707-714 (2009).

Hirst, E. R., Yuan, Y. J., Xu, W. L., Bronlund, J. E., Bond-rupture immunosensors - A review, Biosens. Bioelectron., 23, 12, 1759-1768 (2008).

Hoefelschweiger, B. K., Duerkop, A., Wolfbeis, O. S., Novel type of general protein assay using a chromogenic and fluorogenic amine-reactive probe, Analytical Biochemistry, 344, (1), 122-129 (2005).

Huang Y., Wen, Q., Jiang, J.-H, Shen, G.-L, Yu, R-Q, A novel electrochemical immunosensor based on hydrogen evolution inhibition by enzymatic copper deposition on platinum nanoparticlemodified electrode. Biosens. Bioelectron. 24, 600-605 (2008).

Ionescu, R. E., Gondran, C., Cosnier, S., Gheber, L. A., Marks, R. S., Comparison between the performances of amperometric immunosensors for cholera antitoxin based on three enzyme markers, Talanta, 66, (1), 15-20 (2005).

Iyer, P. V., Ananthanarayan, L., Enzyme stability and stabilization-Aqueous and non-aqueous environment, Process Biochemistry, 43, (10), 1019-1032 (2008).

Jablecki, M., Gough, D. A., Simulations of the frequency response of implantable glucose sensors, Anal Chem., 72, (8), 1853-1859 (2000).

Jacobson, K. B., Biosensors and Other Medical and Environmental Probes, Home page: http://www.ornl.gov/info/ornlreview/rev29 3/text /contents.htm. (Consulted in July 2008).

Jamal, M., Sarac, A. S., Magner, E., Conductive copolymer-modified carbon fibre microelectrodes: electrode characterisation and electrochemical detection of p-aminophenol, Sens. Actuators B: Chemical, 97, (1), 59-66 (2004).

Jiang, X., Li, D., Xu, X., Ying, Y., Li, Y., Ye, Z., Wang, J., Immunosensors for detection of pesticide residues, Biosens. Bioelectron., 23, (11), 1577-1587 (2008).

Kahlert, S., Reiser, G., Glial Perspectives of metabolic states during cerebral hypoxia calcium regulation and metabolic energy, Cell Calcium, 36, (3-4), 295-302 (2004).

Kandimalla, V. B., Neeta, N. S., Karanth, N. G., Thakur, M. S., Roshini, K. R., Rani, B. E. A., Pasha, A., Karanth, N. G. K., Regeneration of ethyl parathion antibodies for repeated use in immunosensor: a study on dissociation of antigens from antibodies, Biosens. Bioelectron. 20, (4), 903-906 (2004).

Khorasani-Motlagh, M., Noroozifar, M., Electrocatalytic Determination of Ascorbic Acid Using Glassy Carbon Modied with Nickel(II) Macrocycle Containing Dianionic Tetraazaannulene Ligand, Turk J Chem, 28, 369-378 (2004).

Kissinger, P. T., Biosensors - A perspective, Biosens. Bioelectron., 20, (12), 2512-2516 (2005). 
Kreuzer, M. P., Pravda, M., O'Sullivan, C, K., Guilbault, G. G., Novel electrochemical immunosensors for seafood toxin analysis, Toxicon, 40, (9), 1267-1274 (2002).

Kros, A., van Hövel, S. W. F. M, Nolte, R. J. M., Sommerdijk, N. A. J. M., A printable glucose sensor based on a poly(pyrrole)-latex hybrid material, Sens. Actuators, B: Chemical, 80, (3), 229-233 (2001).

Kumada, Y., Tomioka, K., Katoh, S., Characteristics of Liposome Immunosorbent Assay (LISA) Using Liposomes Encapsulating Coenzyme bNAD+, J. Chem. Eng. Jpn., 34, (7), 943-947 (2001).

Kutner, W., Wang, J., L'her, M., Buck, R., Analytical Aspects of Chemically Modified Electrodes: Classification, Critical Evaluation and Recommendations, Pure Appl. Chem., 70, (6), 1301-1318 (1998).

Le, D., Feng-Jiang He, Tai Jiao Jiang, Lihua Nie, Shouzhuo Yao, A goat-anti-human IgG modified piezoimmunosensor for Staphylococcus aureus detection, J. Microbiol Meth., 23, (2), 229-234 (1995).

Lei, C. X, Yang, Y, Wang, H., Shen, G. L., Yu, R. Q., Amperometric immunosensor for probing complement III (C3) based on immobilizing C3 antibody to a nano-Au monolayer supported by sol-gel-derived carbon ceramic electrode, Anal. Chim. Acta, 513, (2), 379-384 (2004).

Lesnik, B., Immunoassay Techniques in Environmental Analyses, In: Encyclopedia of Analytical Chemistry R. A. Meyers (Ed.), 26532672 (2000), John Wiley \& Sons Ltd., Chichester (2004).

Leung, A., Shankar, P. M., Mutharasan, R., A review of fiber-optic biosensors, Sensors and Actuators B 125 688-703 (2007).

Li, N., Zhao, H., Yuan, R., Peng, K., Chai, Y., An amperometric immunosensor with a DNA polyion complex membrane/gold nanoparticlesbackbone for antibody immobilization, Electrochimica Acta 54 235-241 (2008).

Liang, R., Qiua, J., Cai, P., A novel amperometric immunosensor based on three-dimensional sol-gel network and nanoparticle self-assemble technique, Anal. Chim. Acta, 534, (2), 8, 223-229 (2005).

Liu Y. C., Wang C. M., Hsiung K.P., Huang C., Evaluation and application of conducting polymer entrapment on quartz crystal microbalance in flow injection immunoassay, Biosens. Bioelectron. 18, 937-942 (2003).

Liu, Y., Meng, S., Mu, L., Jin, G., Zhong, W. and Kong, J., Novel renewable immunosensors based on temperature-sensitive PNIPA Am bioconjugates, Biosens. Bioelectron., 24, 4, 710-715 (2008).

Majid, S., Rhazi, M. E., Amine, A., Curulli, A., Palleschi, G., Carbon Paste Electrode BulkModified with the Conducting Polymer Poly (1,8Diaminonaphthalene): Application to Lead Determination, Microchim. Acta, 143, 195-204 (2003).

Másson, M., Rúnarsson, Ö. V., Jóhannson, F., Aizawa, M., 4-Amino-1-naphthylphosphate as a substrate for the amperometric detection of alkaline phosphatase activity and its application for immunoassay, Talanta, 64, (1), 174-180 (2004).

Matsunaga, T., Ueki, F., Obata, K., Fully automated immunoassay system of endocrine disrupting chemicals using monoclonal antibodies chemically conjugated to bacterial magnetic particles, Anal. Chim. Acta, 475, 75-83 (2003).

Mehrvar, M., Ardi, M., Recent Developments, Characteristics and Potential Applications of Electrochemical Biosensors - Review, Anal. Sci., 20, 1113- 1126 (2004).

Michal, B. M., Buchner, V., Rishpon, J., Electrochemical biosensors for pollutants in the environment, Electroanalysis, 19 2015-2028 (2007).

Miguel, A. G., Rosa, P., Angel, M., On-line immunoanalysis for environmental pollutants: from batch assays to automated sensors, Trends Anal. Chem., 18, 204-218 (1999).

Morgan, C. L., Newman, D. J., Price, C. P., Immunosensors: technology and opportunities in laboratory medicine, Clin. Chem., 42, (2), 193209 (1996).

Nandakumar, V., La Belle, J. T., Reed, J., Shah, M., Cochran, D., Joshi, L, Alford, T. L., A methodology for rapid detection of Salmonella typhimurium using label-free electrochemical impedance spectroscopy, Biosens. Bioelectron. 24, 1045-1048 (2008).

Naqvi, A., Nahar, P., Gandhi, R. P., Introduction of Functional Groups onto Polypropylene and Polyethylene Surfaces for Immobilization of Enzymes, Anal. Biochem. 306, 74-78 (2002).

Neel, T. Le, Moreau, A., Laboisse, C., Truchaud, A., Comparative evaluation of automated systems in immunohistochemistry, Clin. Chim. Acta, 278, (2), 185-192 (1998).

Newman, J. D., Turner, A. P. F., Home blood glucose biosensors: a commercial perspective, Biosens. Bioelectron., 20, (2), 2435-2453 (2005).

Nordin, H., Jungnelius, M, Karlsson, R., Karlsson, O. P., Kinetic studies of small molecule 
interactions with protein kinases using biosensor technology. Anal. Biochem., 340, (2), 15, 359368 (2005).

Ordóñez, S. S., Fàabregas, E., New antibodies immobilization system into a graphitepolysulfone membrane for amperometric immunosensors Biosens. Bioelectron. 22, 965972 (2007).

Pandey, P. C., Upadhyay, S., Shukla, N. K., Sharma, S., Studies on the electrochemical performance of glucose biosensor based on ferrocene encapsulated ORMOSIL and glucose oxidase modified graphite paste electrode, Biosens. Bioelectron., 18, 1257-1268 (2003).

Popescu, C. I., Zetterberg, G., Lo Gorton, Influence of graphite powder, additives and enzyme immobilization procedures on a mediatorless HRP modified carbon paste electrode for amperometric flow-injection detection of $\mathrm{H} 2 \mathrm{O} 2$, Biosens. Bioelectron., 10, 443-461 (1995).

Prieto-Simón, B., M. Campàs, 1, Andreescu, S. and Marty, J. L., Trends in Flow-based Biosensing Systems for Pesticide Assessment, Sensors, 6, 1161-1186 (2006).

Protein structure database: http://www.rcsb.org/pdb/ and http://www.biology.arizona.edu/immunology /tutorials/ antibody/structure.html

Quan, D., Kim, Y., Shin, W., Characterization of an amperometric laccase electrode covalently immobilized on platinum surface, J. Electroanal. Chem. 561, 181-189 (2004a).

Quan, D., Kim, Y., Yoon, K. B., Shin, W., Assembly of Laccase over Platinum Oxide Surface and Application as an Amperometric Biosensor, Bull. Korean Chem. Soc., 23, (3) 385 - 390 (2002).

Quan, D., Shin, W., Modification of electrode surface for covalent immobilization of laccase, Mater. Sci. Eng. C, 24, 113-115 (2004b).

Rabinovich, L., Lev, O., Sol-Gel Derived Composite Ceramic Carbon Electrodes, Electroanalysis, 13, (4), 265 - 274 (2001).

Rao, V. K., Rai, G. P., Agarwal, G. S., Suresh, S., Amperometric immunosensor for detection of antibodies of Salmonella typhi in patient serum, Anal. Chim. Acta, 531, (2), 28, 173-177 (2005).

Richards, E., Bessant, C., Saini, S., Multivariate Data Analysis in Electroanalytical Chemistry, Electroanalysis 14, (22), 1533-1542 (2002).

Rodriguez-Mozaz, S., López de Alda, M. J., Marco, M. P., Barceló, D., Biosensors for environmental monitoring: A global perspective, Talanta, 65, 291-297 (2005).

Sada, E., Katoh, S., Kondo, A., Sohma, Y., Characterization of the immunointeraction and its application to bioaffinity separation. Ann N Y Acad Sci. PMID: 2076021 PubMed-indexed for Medline,(http://www2.kobeu.ac.jp/ katsuda/KRes area/Kaffinity_puriE.html, consulted in May/ 2007) (1990).

Sadana, A., Engineering Biosensors: Kinetics and Design Applications, Academic Press, Chs 1, 4 and 13 (2002).

Sadik, O. A., Wanekaya, A. K., Andreescu, S., Advances in analytical technologies for environmental protection and public safety, J. Environ. Monit. 6, (6), 513 - 522 (2004).

Sadik, O. A., Yan, F., Electrochemical biosensors for monitoring the recognition of glycoprotein-lectin interactions Analytica Chimica Acta, 588, 292296 (2007).

Salinas, E., Torriero, A. A. J., Sanz, M. I., Battaglini, F., Raba, J., Continuous-flow system for horseradish peroxidase enzyme assay comprising a packedcolumn, an amperometric detector and a rotating bioreactor, Talanta 66, (1), 92-102 (2005).

Sarkar, P., Turner, A. P. F., Application of dual-step potential on single screen-printed modified carbon paste electrodes for detection of amino acids and proteins, Fresenius J. Anal Chem 364, 154-159 (1999).

Schmidt, H.-L., Biosensors and flow injection analysis in bioprocess control, J. Biotechnol., 31, (3), v-vi. (1993).

Schuetz, A. J., Winklmair, M., Weller, M. G., Niessner, R., Selection of hapten structures for indirect immunosensor arrays, Fresenius J Anal Chem, 363, 625-631 (1999).

Schugerl, K., Progress in monitoring, modeling and control of bioprocesses during the last 20 years, Journal of Biotechnology, 85, (2) 149-173 (2001).

Shan, G., Lipton, C., Gee, S. J., Bruce, D., Immunoassay, biosensors and other nonchromatographic methods Hammock In: Handbook of Residue Analytical Methods for Agrochemicals p. 623-679, John Wiley \& Sons, Ltd, Chichester (2002).

Shen, G., Wang, H., Tan, S., Li, J., Shen, G., Yu, R., Detection of antisperm antibody in human serum using a piezoelectric immunosensor based on mixed self-assembled monolayers, Anal. Chim. Acta, 540, (2), 279-284 (2005).

Shi, J., Zhu, Y., Zhang, X., Baeyens, W. R. G., García-Campaña, A M., Recent developments in nanomaterial optical sensors, TrAC, Trends Anal. Chem, 23, (5), 351-360 (2004).

Shipway, P. H., Ngao, N. K., Microscale abrasive wear of polymeric materials Wear 255, (1-6), 742-750 (2003). 
Shriver-Lake, L. C., Donner, B., Edelstein, R., Breslin, K., Bhatia, S. K., Ligler, F. S., Antibody immobilization using heterobifunctional crosslinkers, Biosens. Bioelectron., 12, (11), 1101-1106 (1997).

Skládal, P., Piezoelectric Quartz Crystal Sensors Applied for Bioanalytical Assays and Characterization of Affinity Interactions, J. Braz. Chem. Soc. 14, (4), 491-502 (2003).

Skottrup, P. D., Nicolaisen, M., Justesen, A. F., Towards on-site pathogen detection using antibody-based sensors, Biosens. Bioelectron, 24, (3), 339-348 (2008).

Stefan, R. I., Staden, J. F., Aboul-Enein, H. Y., Estimation of uncertainties for the application of electrochemical sensors in clinical analysis, Accred Qual Assur, 8, 86-89 (2003).

Stiene, M., Bilitewski, U., Electrochemical characterization of screen-printed carbonaceous electrodes for the determination of peroxidase activity in novel screen-printed flow-through modules, Anal Bioanal Chem 372, 240-247 (2002).

Stolper, S. I., Mark, S. S., Park, J. Y. and Kricka, L. J., Nanotechnology and Immunoassay, Clinical Chemistry 53, 1874 (2007).

Stradiotto, N. R., Yamanaka, H., Valnice, M., Zanoni, B., Electrochemical Sensors: A Powerful Tool in Analytical Chemistry, J. Braz. Chem. Soc. 14, (2), 159-173 (2003).

Su, X., Chew, F. T., Li, S. F. Y., Design and Application of Piezoelectric Quart Crystal-based Immunoassay, Anal. Sci., 16, 107-114 (2000).

Subramanian, G., In: Antibodies Production and Purification: Production and Purification, Vol 1 G. Subramanian (Editor) (2004).

Susmel S., Toniolo R., Pizzariello A., Dossi N., Bontempell G., A piezoelectric immunosensor based on antibody entrapment within a non-totally rigid polymeric film Sensors and Actuators B: Chemical, 111-112, (11), 331-338 (2005).

Suzuki, M., Ozawa, F., Sugimoto, W., Aso, S., Miniaturization of SPR Immunosensors, Anal. Sci. 17 Supplement i265 - i267 (2001).

Tang, D., Yuan, R. and Chai, Y., Magnetic Control of an Electrochemical Microfluidic Device with an Arrayed Immunosensor for Simultaneous Multiple Immunoassays, Clinical Chemistry 53, (7), 1323-1329 (2007).

Tedeschi, L., Domenici, C., Ahluwalia, A., Baldini, F., Mencagli, A., Antibody immobilisation on fibre optic TIRF sensors, Biosens. Bioelectron. 19, 85-93 (2003).

Theâvenot, D. R., Toth, K., Durst, R. A., Wilson, G. S., Electrochemical Biosensors: Recommended
Definitions and Classification, Pure Appl. Chem. 71 (12), 2333 -2348 (1999).

Tijssen, P., Practice and theory of enzyme immunoassays. In Laboratory Techniques in Biochemistry and Molecular Biology, vol. 15. Elsevier, Amsterdam, (1985).

Tschmelak, J., Proll, G., Riedt, J., Kaiser, J., Kraemmer, P., Barzaga, L., Wilkinson, J. S., Ping Hua, Hole, J. P., Nudd, R., Jackson, M., Abuknesha, R., Barcelo, D., Rodriguez-Mozaz, S., Lopez de Alda, M. J., Sacher, F., Stien, J., Slobodnik, J., Oswald, P., Kozmenko, H., Korenkova, E., Tothova, L., Krascsenits, Z., Gauglitz, G., Automated Water Analyser Computer Supported System (AWACSS) Part I: Project objectives, basic technology, immunoassay development, software design and networking, Biosens. Bioelectron. 20, (8), 14991508, (2005).

Turner, A. P. F., Karube, I., Wilson, G. S., Biosensors: Fundamentals and Applications, eds., Oxford University Press: Oxford, chap. 2 (1987).

Velasco-Garcia, M. N., Mottram, T., Biosensor Technology addressing Agricultural Problems, Biosystems Engineering, 84, (1), 1-12 (2003).

Walcarius, A., Analytical Applications of SilicaModified Electrodes - A Comprehensive Review, Electroanalysis, 10, (18), 1217-235 (1998).

Wang, C., Wang, H., Wu, Z., Shen, G., Yu R., A piezoelectric immunoassay based on selfassembled monolayers of cystamine and polystyrene sulfonate for determination of Schistosoma japonicum antibodies, Anal Bioanal Chem, 373: 803-809 (2002).

Wang, H., Meng, S., Guo, K., Liu, Y., Yang, P., Zhong, W., Liu, B., Microfluidic immunosensor based on stable antibody-patterned surface in PMMA microchip, Electrochemistry Communications, 10, 3, 447-450 (2008).

Wang, J., Tian, B. M., Rogers, K. R., Thick film electrochemical immunosensor based on stripping potentiometric detection of a metal ion label, Anal. Chem., 70, 1682-1685 (1998).

Wang, S., Wu, Z., Zhang, F. Q. S., Shen, G., Yu, R., A novel electrochemical immunosensor based on ordered $\mathrm{Au}$ nano-prickle clusters, Biosens. Bioelectron., 24, (4), 1026-1032 (2008).

Wang, Z., Tua, Y., Liu, S., Electrochemical immunoassay for $\alpha$-fetoprotein through a phenylboronic acid monolayer on gold, Talanta, 77, 815-821 (2008).

Warsinke, A., Benkert, A., Scheller, F. W., Electrochemical immunoassays, Fresenius J. Anal. Chem., 366, 622-634 (2000). 
Wightman, R. M., Runnels, P., Troyer, K., Analysis of chemical dynamics in microenvironments, Anal. Chim. Acta, 400, (1-3), 5-12 (1999).

Wilson, G. S., Gifford, R., Biosensors for real-time in vivo measurements, Biosens. Bioelectron. 20, (2), 2388-2403 (2005).

Wu, Y., Zheng, J., Li, Z., Zhao, Y., Zhang, Y., A novel reagentless amperometric immunosensor based on gold nanoparticles/TMB/Nafionmodified electrode, Biosens. Bioelectron, 24, (5), 1389-1393, (2009).

Yoon, H. C., Yang, H., Byun, S. Y., Ferritin Immunosensing on Microfabricated Electrodes Based on the integration of immunoprecipitation and electronical signaling reactions. Anal. Sci. 20, 1249-1253 (2004).

Zhou, Y.-M, Hu, S. Q., Shen, G. L, Qin, Y. R., An amperometric immunosensor based on an electrochemically pretreated carbon-paraffin electrode for complement III (C3) assay, Biosens. Bioelectron. 18, 473-481 (2003a).
Zhou, Y.-M., Wu, Z.-Y., Shen, G.-L., Yu Ru-Qin, An amperometric immunosensor based on Nafionmodified electrode for the determination of Schistosoma japonicum antibody, Sens. Actuators B: Chem. 89, 292-298 (2003b).

Zhou, Y.-M, Wu Zhao-Yang, Shen G.-L., Yu, Ru-Qin, An amperometric immunosensor based on a Conducting Electrode for the Determination of Schistosoma japonicum antigen. Anal. Sci. 18, 155159 (2002).

Zhu, P., Shelton, D. R., Karns, J. S., Sundaram, A., Li S., Amstutz, P., Tang, C, Detection of waterborne E. coli $\mathrm{O} 157$ using the integrating waveguide biosensor, Biosens. Bioelectron. 21, (4), 678-683 (2005).

Zhuo, Y., Yuan, R., Chai, Y., Tang, D., Zhang Y, Wang N., Li X., Zhu Q., A reagentless amperometric immunosensor based on gold nanoparticles/ thionine/Nafion-membrane modified gold electrode for determination of $\alpha$-1-fetoprotein, Electrochemistry Communications, 7 (4), 355-360 (2005). 